$1 \quad$ Number of text pages: 52

2 Number of figures: 7

3 Running title: $Z n$ isotopic fractionation in plants

4 Corresponding author: Cristina Caldelas

5 Address: Department of Evolutionary Biology, Ecology, and Environmental Sciences

6 University of Barcelona

$7 \quad$ Av. Diagonal 643

808028 Barcelona (Spain)

9 Phone: +34 934021462

$10 \quad$ Fax: +34934112842

11 Email: criscaldelas@ub.edu 


\section{Zinc Homeostasis and Isotopic Fractionation in Plants: A review}

\section{Keywords}

16 Copper, Iron, Nickel, Stable isotopes, Zinc deficiency, Zinc tolerance

Abstract

Aims: Recent advances in mass spectrometry have demonstrated that higher plants discriminate stable $\mathrm{Zn}$ isotopes during uptake and translocation depending on environmental conditions and physiological status of the plant. Stable $\mathrm{Zn}$ isotopes have emerged as a promising tool to characterize the plants response to inadequate $\mathrm{Zn}$ supply. The aim of this review is to build a comprehensive model linking $\mathrm{Zn}$ homeostasis and $\mathrm{Zn}$ isotopic fractionation

24 in plants and advance our current view of $\mathrm{Zn}$ homeostasis and interaction with other 25 micronutrients. Methods: The distribution of stable $\mathrm{Zn}$ isotopes in plants and the most likely 26 causes of fractionation are reviewed, and the interactions with micronutrients $\mathrm{Fe}, \mathrm{Cu}$, and $\mathrm{Ni}$ 27 are discussed. Results: The main sources of $\mathrm{Zn}$ fractionation in plants are i) adsorption, ii) 28 low- and high-affinity transport phenomena, iii) speciation, iv) compartmentalization, and v) 29 diffusion. We propose a model for $\mathrm{Zn}$ fractionation during uptake and radial transport in the roots, root-to-shoot transport, and remobilization. Conclusions: Future work should concentrate on better understanding the molecular mechanisms underlying the fractionations as this will be the key to future development of this novel isotope system. A combination of stable isotopes and speciation analyses might prove a powerful tool for plant nutrition and

34 homeostasis studies.

\section{Abbreviations}

37 COPT $=$ Copper Transporter 
DMA = Deoxymugineic acid

EXAFS $=$ Extended $X-$ Ray Absorption Fine Structure

$40 \quad$ FRO $=$ Ferric Reductase Oxidase

$41 \quad \mathrm{HMA}=$ Heavy $M$ etal ATPase

$42 \quad$ IRT = Iron-Regulated Transporter

43 M C-ICP-M S = M ulti-Collector Induced Coupled Plasma Mass Spectrometry

$44 \quad$ M TP $=$ M etal Tolerance Protein

$45 \quad$ PS $=$ Phytosiderophores

$46 \quad$ YS = Yellow Stripe

$47 \quad$ YSL = Yellow Stripe-Like

$48 \quad$ ZIF $=$ Zinc-Induced Facilitators

$49 \quad$ ZIP $=$ ZRT-IRT-like Protein

\section{Introduction}

52 Zinc is an essential micronutrient for living organisms with several crucial functions in the cell.

53 It is the only metal present in enzymes of all six major classes, playing catalytic, regulatory, and

54 structural roles (Vallee and Auld 1992; Coleman 1992). Zinc is furthermore involved in the regulation of DNA transcription, and the transduction of intra- and intercellular signalling

56 (Broadley et al. 2007; M aret 2013). Unfortunately, Zn deficiency is widespread in arable soils

57 worldwide (Alloway 2009) due to various factors such as high $\mathrm{pH}(>7)$, low plant available Zn

58 content, prolonged flooding, low redox potential, and high contents of organic matter,

59 bicarbonate and phosphorus (P) (Neue and Lantin 1994; Ova et al. 2015). It is not surprising

60 that around $17 \%$ of the world population is at risk of insufficient $\mathrm{Zn}$ intake based on food

61 supply data, although actual deficiency rates are likely to be much higher (Wessells and Brown

62 2012; Kumssa et al. 2015). This makes Zn deficiency one of the most pressing causes of

63 malnutrition. The consequences for the public health and the economy of the affected areas 
are severe. In young children, Zn deficiency leads to stunting and increased susceptibility to diarrhoea, pneumonia, and malaria, causing 800,000 early deaths yearly (Caulfield et al. 2006). Zinc deficiency in crops causes root apex necrosis, leaf disorders, reduction of biomass, delayed maturity, yield reduction, and high mortality (Van Breemen and Castro 1980; Wissuwa et al. 2006; Broadley et al. 2007; Singh and Singh 2011; Al-Fahdawi et al. 2014; M attiello et al. 2015; Fu et al. 2015). Strategies like crop biofortification (increasing Zn content in edible parts during growth) or breeding for varieties tolerant to $\mathrm{Zn}$-deficiency might help to overcome $\mathrm{Zn}$ deficiency in soils. To this end, it is crucial to increase our current level of understanding about the mechanisms involved in $\mathrm{Zn}$ uptake and metabolization by plants. The study of stable $\mathrm{Zn}$ isotope fractionation is a novel technique that is already helping us to understand better the mechanisms of $\mathrm{Zn}$ uptake, translocation, and tolerance in plants, and how these react to the environment. However, a comprehensive model linking $\mathrm{Zn}$ homeostasis and $\mathrm{Zn}$ isotopic fractionation in plants and considering the interactions with other micronutrients is still 77 missing.

Here we review our present understanding of Zn isotopic fractionation in plants and compare it with other micronutrients and their isotopic systems, with the aim of advancing our current view of Zn homeostasis and interaction with other micronutrients.

\section{Zinc isotopic fractionation in plants}

83 The concentration of $\mathrm{Zn}$ in plant tissues must stay within a specific range to preserve the structural cohesion and metabolic functions of the cells. The lower end is typically around

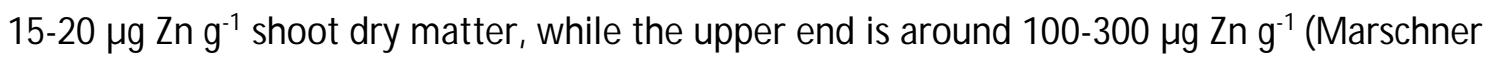
1995; Broadley et al. 2012). In the cytoplasm of the plant cells, the concentration of free $\mathrm{Zn}^{2+}$ is kept very low (in the pM range) (Maret 2015), because it tends to bind to cellular components. Higher concentrations could eventually disrupt the cytosolic metabolism and restrict $\mathrm{Zn}$ transport to satisfy the demands of sink organs, tissues, cells, and organelles. Plants have 
developed several mechanisms to adapt to the fluctuations of the $\mathrm{Zn}$ available for them in the

91 growth environment, and to maintain the intracellular levels of $\mathrm{Zn}$ stable within the optimal

92 range. These are jointly known as Zn homeostasis. The amount of Zn taken up by the roots and transferred to the shoot is tightly controlled thanks to an intricate network of barriers, transporters, chelators, and compartments (Sinclair and Krämer 2012; Olsen and Palmgren 2014; Ricachenevsky et al. 2015). Zinc movement through the plants consequently leads to isotope discrimination.

97 Stable isotopes of light elements like $\mathrm{C}, \mathrm{N}, \mathrm{O}$, and $\mathrm{S}$ have been long used to study plant physiology and its response to the environment (Mekhtiyeva and Pankina 1968; Deniro and Epstein 1979; Farquhar et al. 1982; Mariotti et al. 1982). A new generation of mass spectrometers (MC-ICP-MS) has enabled the use of stable isotopes to study $\mathrm{Zn}$, copper (Cu), iron (Fe), nickel (Ni), calcium, and magnesium (Weiss et al. 2005; Wiegand 2005; Guelke and von Blanckenburg 2007; Black et al. 2008; Weinstein et al. 2011; Deng et al. 2014). Most progress has been made for $\mathrm{Zn}$. Fractionation of $\mathrm{Zn}$ stable isotopes in plants was first reported during $\mathrm{Zn}$ uptake by the root and translocation to the shoots in hydroponically grown tomato (Solanum lycopersicum L.), lettuce (Lactuca sativa L.), and rice (Oryza sativa L.) (Weiss et al. 2005). Roots accumulated heavy isotopes relative to the solution, while the lighter isotopes were enriched in the shoots compared to the roots and differences in root-to-shoot fractionation were observed among species (Weiss et al. 2005). In soils, a survey of six species collected from a pristine water-shed in Cameroon showed that both roots and shoots were isotopically heavier than the top soil, with only one species showing root-to-shoot

111 fractionation (Megaphrynium macrostachyum) (Viers et al. 2007). In the same survey, the

112 leaves of trees were isotopically lighter than the rest of the plant, and a relationship between

113 the height of the leaves and the magnitude of the fractionation was suggested. This hypothesis

114 was later supported by a study using bamboo (Phyllostachys aurea Rivière \& C. Rivière), where 115 the light isotopes were progressively enriched in leaves with height (Moynier et al. 2009). 
116 Subsequent studies demonstrated that isotope discrimination by plants changes in response to

117 Zn availability in the environment. In rice, response to Zn deficiency resulted in changes in the

118 fractionation pattern, and the shoots of Zn-deficient plants accumulated more heavy isotopes 119 than the controls (Arnold et al. 2010). In reeds (Phragmites australis [Cav.] Trin. ex Steud.), Zn 120 excess also caused alteration of the isotopic fractionation, and the aerial parts of plants grown 121 in Zn-polluted solution were isotopically light as compared with the controls (Caldelas et al. 122 2011). Taken together, these findings show that $\mathrm{Zn}$ stable isotopes can be used to identify and quantify metal uptake or transport mechanisms and to assess the influence of factors such as environmental changes, physiological status, and species on these mechanisms.

\section{Determination of accurate and precise $\mathrm{Zn}$ stable isotope ratios in plants}

127 The MC-ICP-MS (multi-collector inductively coupled plasma - mass spectrometer) is a plasma source mass spectrometer with an array of collectors used to measure the isotope ratios of micronutrients. The instrument typically consists of three parts: an ion source, a mass analyser, and a detector. The ion source is a high-temperature argon plasma that ionizes the element.

131 The mass analyser has two sectors (electrostatic and magnetic) that focus the ion beam and separate the ions for their mass-to-charge ratio. The detector unit consists of an array of Faraday cups that can measure different ion beams simultaneously. This multi-collector (MC) array permits to measure all the isotopes of an element at the same time and increases precision to $0.001 \%$ for the isotope ratios. An exhaustive description of the MC-ICP-MS technique is found in Vanhaecke et al. 2009.

137 Mass spectrometers favour the transmission of the heavy isotopes inducing a mass-bias. The 138 sample preparation can also cause mass fractionation. There are different strategies to correct 139 for mass-bias shifts: direct sample-standard bracketing (SSB), doping with an external element, 140 and using a double-spike. In the direct SSB method, a standard is analysed before and after the 141 sample and used to correct the shift. The mass-bias must be constant over time and the 
142 sample must be very pure to minimize matrix effects. If mass fractionation changes over time,

143 a doping element with a mass similar to that of $\mathrm{Zn} \mathrm{(} \mathrm{Cu}$ is commonly used) may be mixed with

144 the sample to correct for mass bias. This external correction is based on the assumption that

145 the ratio of the mass fractionation of both elements stays constant during the analysis period

146 (Maréchal et al. 1999). In the double-spike correction, a spike containing two Zn isotopes is

147 added to the sample prior to sample preparation. The isotope ratio of the mixture is then

148 compared with that of the double-spike. The application of these various correction methods

149 to Zn stable isotope analysis has been described elsewhere(Albarède and Beard 2004).

150 Zinc isotope fractionation is commonly expressed using the delta notation, where the isotopic

151 ratio of the sample (e.g., ${ }^{66} \mathrm{Zn} /{ }^{64} \mathrm{Zn}$ ) is compared with that of a standard (e.g. the widely used

152 JMC 3-0729L Zn) and expressed in parts per thousand (\%o) using Eqn. 1:

$153[1]$

$$
\delta^{66} \mathrm{Zn}_{\text {sample }}=\left[\frac{\left({ }^{66} \mathrm{Zn} /{ }^{64} \mathrm{Zn}\right)_{\text {sample }}}{\left({ }^{66} \mathrm{Zn} /{ }^{64} \mathrm{Zn}\right)_{\text {standard }}}-1\right] \cdot 10^{3}
$$

155 The $\mathrm{Zn}$ isotopic fractionation between two samples ( $i$ and $j$ ) is calculated using Eqn. 2:

$156[2]$

$$
\Delta^{66} Z n_{i-j}=\delta^{66} Z n_{i}-\delta^{66} Z n_{j}
$$

The IRM M 3702 standard has been proposed as the new first-choice reference material to substitute the Johnson-Matthey Zn standard 3-0749L (JMC) (Moeller et al. 2012), of which there is little left. However, JMC is still the standard most widely used in the literature and most of authors did not analyse IRM M 3702. For this reason, all the $\delta^{66} \mathrm{Zn}$ values in this review

163 are expressed relative to the JMC standard. Equation 3 was used to convert between 164 standards (Criss 1999): 


$$
\delta X_{J M C}=\delta X_{S t}+\delta S t_{J M C}+\frac{1}{10^{3}}\left(\delta X_{s t}\right) \cdot\left(\delta S t_{J M C}\right)
$$

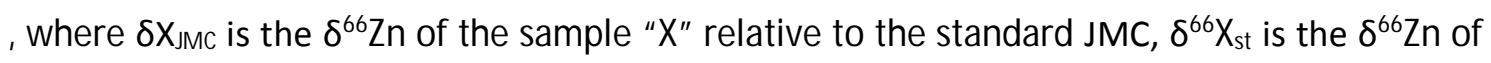

169 the same sample relative to the standard "St", and $\delta \mathrm{StJMc}$ is the $\delta^{66} \mathrm{Zn}$ of the same standard

170 relative to JMC. The data from each individual publication, was converted using the $\delta S_{\mathrm{J} J \mathrm{MC}}$

171 provided by the authors. This was of $0.044 \pm 0.035 \%$ to $0.09 \pm 0.05 \%$ for the in-house standard

172 Johnson-M atthey Purontronic ${ }^{\mathrm{TM}}$ Batch NH 27040 (Weiss et al. 2005; Arnold et al. 2010; Jouvin

173 et al. 2012), $0.04 \pm 0.02 \%$ for the in-house standard London Zn (Smolders et al. 2013), and

$1740.27 \pm 0.08 \%$ o to $0.28 \pm 0.05 \%$ for the reference material IRM M 3702 (Tang et al. 2012; Tang et 175 al. 2016).

176 For $\mathrm{Fe}, \mathrm{Cu}$, and $\mathrm{Ni}$ the same $\delta$ notation is used, and $\delta$ values refer to the isotopic ratios

$177{ }^{56} \mathrm{Fe} /{ }^{54} \mathrm{Fe},{ }^{65} \mathrm{Cu} /{ }^{63} \mathrm{Cu}$, and ${ }^{60} \mathrm{Ni} /{ }^{58} \mathrm{Ni}$, respectively, and are expressed relative to the standards IRM M-14 (Fe), NIST-SRM 976 (Cu), and NIST-SRM 986 (Ni).

\section{Isotopic fractionation of $\mathrm{Zn}$ during uptake by plants}

Zinc binding to the cell wall

182 The first evidence of $\mathrm{Zn}$ fractionation during $\mathrm{Zn}$ uptake by plants was provided by Weiss and colleagues (Weiss et al. 2005). They used rice, lettuce, and tomato grown hydroponically in EDTA- (1 $\mu$ M Zn) or HEDTA- (2 $\mu$ M Zn) solutions, and observed that ${ }^{66} \mathrm{Zn}$ was similarly enriched in the roots of all three species regardless of the nutrient solution $\left(\Delta^{66} \mathrm{Zn}_{\text {root-solution }}=0.08\right.$ to $0.16 \%$ )(Fig. 1). This distribution of $\mathrm{Zn}$ isotopes was attributed to ${ }^{66} \mathrm{Zn}$ preferential adsorption onto the root surface or binding to cell walls, together with the preferential uptake of isotopically light $Z \mathrm{n}^{2+}$ into the root cells. Subsequently, in durum wheat (Triticum durum Desf.) and tomato, very similar $\Delta^{66} \mathrm{Zn}_{\text {root-solution }}$ were obtained $(-0.02$ to $0.15 \%)$ in EDTA solution with 1.6 or $0.62 \mu \mathrm{M}$ Zn (Jouvin et al. 2012). These results from hydroponic studies agree with data obtained from the natural environment. Viers et al. 2007 surveyed six plant species including 
192 herbaceous and trees growing in a tropical watershed in Cameroon. All roots were isotopically

193 heavier than the soils (ranging between 0.09 and 0.64\%) (Fig. 2). In larch trees (Larix gmelinii

194 [Rupr.] Rupr.) from pristine Siberian forests, the fractionation between roots and soil was of

$0.26 \%$ (Viers et al. 2015). Several other authors have reported the accumulation of heavy isotopes in the roots (up to $0.8 \%$ ) with respect to the source of $\mathrm{Zn}$ in a variety of species and experimental set-ups (Aucour et al. 2011; Caldelas et al. 2011; Tang et al. 2012; Smolders et al. 2013; Houben et al. 2014; Couder et al. 2015; Aucour et al. 2015; Tang et al. 2016). Since these studies submitted plants to conditions of either Zn deficiency or Zn excess, they will be discussed in detail in sections 4.3 and 6.

Strong evidence of isotopic fractionation during $\mathrm{Zn}$ adsorption to cell walls has been obtained from laboratory experiments conducted with diatoms. Four species of marine and freshwater diatoms showed accumulation of ${ }^{66} \mathrm{Zn}$ in the unwashed cells with respect to the solution, with $\Delta^{66} \mathrm{Zn}_{\text {diatom-solution }}$ ranging between 0.08 and $0.43 \%$ (Gélabert et al. 2006). The offset was attributed to adsorption of $\mathrm{Zn}$ onto the cell surface, and $\mathrm{Zn}$ adsorption modelling showed that Zn would mostly bind to the carboxylate groups of the cell walls. In the same line, the unwashed cells of the marine diatom Thalassosiera oceanica (Hasle) were isotopically heavier $\left(\delta^{66} \mathrm{Zn}=-0.05\right.$ to $0.38 \%$ ) than EDTA-washed cells $(-0.79$ to $-0.16 \%)$ (John et al. 2007). The fraction of $\mathrm{Zn}$ adsorbed to $\mathrm{T}$. oceanica was isotopically heavier than the solution, and the fractionation increased linearly with $\mathrm{Zn}$ concentration $[\mathrm{Zn}]\left(\Delta^{66} \mathrm{Z} \mathrm{n}_{\text {diatom-solution }}\right.$ from $0.09 \%$ at

$21110^{-11.5} \mathrm{M}$ to $0.52 \%$ at $\left.10^{-8.5} \mathrm{M}\right)\left(\mathrm{J}\right.$ ohn et al. 2007). The $\Delta^{66} \mathrm{Zn}_{\text {diatom-solution }}$ from both studies is remarkably similar, and points to the preferential adsorption of heavy $\mathrm{Zn}$ isotopes onto the cell

213 surface, probably to the carboxylate groups of the cell walls. Zinc binding to carboxyl and 214 hydroxyl groups of pectin and to hydroxyl groups of cellulose in the cell walls of roots has been 215 confirmed in tobacco plants (Nicotiana tabacum L.) using chemical extracts and Extended 216 X-Ray Absorption Fine Structure (EXAFS) spectrometry (Straczek et al. 2008). It is thus very 217 likely that the enrichment in heavy $\mathrm{Zn}$ isotopes observed in plants roots is mostly generated 
218 during $\mathrm{Zn}$ binding to the hydroxyl and carboxyl groups of the cell walls, similarly to what

219 happens in diatoms. The isotopic fractionation between plants roots and the solution where

220 they grow $\left(\Delta^{66} \mathrm{Zn}_{\text {root-solution }}=-0.15 \%\right.$ o to $0.8 \%$ ) is in a similar range to that of diatoms relative to

221 the solution $\left(\Delta^{66} \mathrm{Zn}_{\text {diatom-solution }}=0.08 \%\right.$ o to $0.52 \%$ ). The wider spread of $\Delta^{66} \mathrm{Zn}$ root-solution could be explained by the larger $[\mathrm{Zn}]$ in the solutions (up to $10^{-5} \mathrm{M}$ ), and species-specific differences in the composition and adsorption capacity of the cell walls. To test this hypothesis, we need to constrain the isotopic fractionation during $\mathrm{Zn}$ binding to the cell walls of plants and their majoritarian components cellulose and pectine.

Low- and high-affinity transport phenomena

The shoots of hydroponically grown rice, tomato, and lettuce were depleted in ${ }^{66} \mathrm{Zn}$ relative to ${ }^{64} \mathrm{Zn}$ ranging from -0.25 to $-0.56 \%$ and differing between species (Weiss et al. 2005)(Fig. 1). Analogous results were later obtained in tomato and durum wheat with $\Delta^{66} \mathrm{Z} \mathrm{n}_{\text {shoot-root }}$ ranging between -0.29 and $-0.56 \%$ (J ouvin et al. 2012; Smolders et al. 2013). This shift was attributed to the preferential transport of free $\mathrm{Zn}^{2+}$ across cell membranes by transport proteins. The cell walls of root cells closely touch one another forming a single extracellular space termed root apoplast, in which water and solutes can circulate freely. This movement is restricted by the endodermis, a single layer of cells that surrounds the conductive tissue of the root. The Casparian strip, a ring of impermeable material found in the cell walls of the endodermis prevents $\mathrm{Zn}$ from reaching the shoots via the apoplastic pathway. Hence, $\mathrm{Zn}$ has to be transported across the cell membrane of the root cells. The cell membrane consists of a phospholipid bilayer, and its hydrophobic nature impedes the passive diffusion of dissolved ions into the cell. Ion uptake must be facilitated by transporter proteins, which allow plant

241 cells to control their concentration in the cytoplasm. Zinc transport across the cell membranes

242 is tightly controlled by plasma membrane associated proteins, mainly those from the ZIP family

243 (ZRT-IRT-like Proteins). Transporters AtIRT1 and AtIRT3 (Iron Regulated Transporter) in 
244 arabidopsis (Arabidopsis thaliana [L.] Heynh.), HvZIP7 in barley (Hordeum vulgare L.), and 245 OsIRT1, OsZIP1, OsZIP3, and OsZIP5 in rice are expressed in the root epidermis and involved in 246 Zn uptake from the rhizosphere into the cell (Korshunova et al. 1999; Vert et al. 2002; Ishimaru 247 et al. 2006; Lin et al. 2009; Lee et al. 2010; Tiong et al. 2014).

248 There are no isotope data on isolated plant cells (protoplasts) to help us understand how the membrane transporter proteins could discriminate $\mathrm{Zn}$ isotopes. Experiments on diatoms (single cell algae) might be a good approximation, since the functioning of $\mathrm{Zn}$ transporters is similar. Early work in diatoms suggested that plasma membrane transporters discriminate between Zn isotopes (Gélabert et al. 2006; John et al. 2007). Cells of marine diatoms washed in EDTA to remove the extracellular Zn were isotopically light as compared with the solution, which was attributed to fractionation during $\mathrm{Zn}$ uptake. Moreover, the $\Delta^{66} \mathrm{Zn}_{\text {solution-diatom }}$ increased with [Zn], following a sigmoidal curve (John et al. 2007). The switch of this curve took place around $10^{-10} \mathrm{M} \mathrm{Zn}$, coinciding with the switch between suggested "high- and low-affinity" Zn uptake reported for marine diatoms (Sunda and Huntsman 1992). Transport characterized as "high-affinity" predominates at low [Zn], whereas low-affinity transport prevails at high [Zn]. In the algae study conducted by John and co-workers, high-affinity $\mathrm{Zn}$ uptake generated an isotopic fractionation of up to $-0.2 \%$ at $\mathrm{Zn}$ levels below $10^{-10.5} \mathrm{M}$ (J ohn et al. 2007). In contrast, low-affinity transport caused a much greater fractionation (up to $-0.8 \%$ ) at $[\mathrm{Zn}]$ above $10^{-9.5} \mathrm{M}$. It was argued that during higher efficiency transport most of the $\mathrm{Zn}$ within reach is transported regardless of the isotope. This would explain the smaller isotopic fractionation during Zn uptake when high-affinity transport predominates (John et al. 2007). High- and low-affinity transport phenomena have been described in rice, wheat, and other plants (Hacisalihoglu et al. 2001; Milner et al. 2012; Meng et al. 2014). The high-affinity transport was reported to predominate at less than $10^{-8} \mathrm{M} Z \mathrm{n}$ in the growth medium for wheat

268 (Hacisalihoglu et al. 2001) and less than $10^{-7} \mathrm{M}$ in rice (M eng et al. 2014). The [Zn] in the hydroponic studies was around $10^{-7}-10^{-6} \mathrm{M}$ (Weiss et al. 2005; Jouvin et al. 2012; Smolders et 
270 al. 2013). At these $\mathrm{Zn}$ levels a higher contribution of low-affinity transport would be expected

271 in wheat. In the above studies the root-to-shoot fractionation ( $\Delta^{66} Z n_{\text {shoot-root }}$ ) was mainly

272 attributed to $\mathrm{Zn}$ uptake into the plant by the root cells, so we can compare it to $\Delta^{66} \mathrm{Zn}$ in-ex in

273 diatoms. The $\Delta^{66} \mathrm{Zn}$ shoot-root ranged from -0.25 to $-0.56 \%$ for all plants, approximately between

274 that of high- and low-affinity transport in marine diatoms $(-0.2 \%$ and $-0.8 \%$, respectively)

275 (John et al. 2007). Moreover, wheat had lower $\Delta^{66} \mathrm{Zn}_{\text {shoot-root }}(-0.29 \%$ to $-0.51 \%$ o $)$ than rice

$276(-0.25 \%$ o to $-0.29 \%$ ) (Weiss et al. 2005; Jouvin et al. 2012)(Fig. 1). It is noteworthy that the

277 extent of the fractionation between shoots and roots increased with increasing [Zn], as

$278 \Delta \Delta^{66} \mathrm{Zn}_{\text {in-ex }}$ did in diatoms (John et al. 2007). It is highly plausible that the ion selectivity of the

279 membrane transport proteins like ZP transporters is the predominant molecular mechanism

280 responsible for the isotopic fractionation observed during Zn uptake at the root.

281

282 The use of $\Delta^{66} \mathrm{Zn}_{\text {shoot-root }}$ as a proxy of isotopic fractionation during $\mathrm{Zn}$ uptake by plants serves

283 well the purpose of elucidating the contribution of plants to isotope partitioning during $\mathrm{Zn}$

284 biogeochemical cycling. However, neither $\Delta^{66} Z n_{\text {shoot-root }}$ nor $\Delta^{66} Z n_{\text {shoot-solution }}$ separate the

285 isotopic effect of Zn uptake from those caused by the mechanisms of $\mathrm{Zn}$ transfer from the root

286 to the shoot (discussed in section 5.1). Therefore these parameters provide an insufficient

287 level of detail for future physiological studies. To better quantify the discrimination of $\mathrm{Zn}$

288 isotopes occurring during $\mathrm{Zn}$ uptake into the root symplast we need to isolate this isotopic

289 effect from any others. This could be achieved by reproducing the diatom studies using

290 protoplasts, comparing the isotope ratios of wild type plants with mutant lines defective for

291 known Zn transporters, measuring isotopic fractionation during Zn binding to relevant ligands,

292 and analysing the isotope ratios of the cytoplasm, the vacuoles, and the xylem sap.

294 Uptake of Zn complexes in Zn-deficient plants 
295 Quantum mechanics predicts that the mass of atoms affects the strength of chemical bonds

296 (White 2015). The molecule with the heavy isotope has lower vibrational frequency and hence

297 lower dissociation energy. This generally leads to the accumulation of heavy isotopes in the

298 complexed form, as seen during the formation of $\mathrm{Zn}$ complexes with EDTA $\left(\Delta^{66} \mathrm{Z} \mathrm{n}_{\mathrm{Zn}-\mathrm{L}-}\right.$

$\left.299 \mathrm{Zn}^{2+}=0.33 \%\right)$ and deoxymugineic acid (DMA) (0.30\%o)(Markovic et al. 2016). In a field study

300 using soil with low $\mathrm{Zn}$ available, ${ }^{66} \mathrm{Zn}$ was enriched in the shoots of a rice variety tolerant to $\mathrm{Zn}$

301 deficiency (RIL46) compared with the soil $\left(\Delta^{66} \mathrm{Zn}_{\text {shoot-soil }}=0.21 \%\right)$ and the shoots of intolerant

302 plants $\left(\Delta^{66} \mathrm{Zn}_{\text {int-tol }}=0.13 \%\right.$ ) (Arnold et al. 2010)(Fig. 2). This was tentatively attributed to $\mathrm{Zn}$

303 uptake in form of complexes with DMA. The roots of RIL46 release more DM A in response to

304 Zn deficiency than a Zn-deficiency sensitive rice variety, IR74 (1.2 vs $0.4 \mu \mathrm{mol}$ DM A g ${ }^{-1}$ root DW

$\left.3054 h^{-1}\right)($ Widodo et al. 2010). Phytosiderophores (PS) like DMA are small molecular weight

306 compounds excreted by the roots of plants from the Poaceae family (Strategy II plants) in

307 response to Fe deficiency (Takagi 1976; Marschner et al. 1986; Takagi et al. 2008). The PS

308 solubilize Fe from soil and form PS-Fe complexes, which are then taken up by the root cells by

309 means of specific plasma membrane transporters of the OPT (Oligopeptide Transporter) family

310 (Lubkowitz 2011). Examples are ZmYS1 in maize (Zea mays L.), HvYS1 in barley, and OsYSL15 in

311 rice (M urata et al. 2006; Ueno et al. 2009; Inoue et al. 2009; Suzuki et al. 2012). To date no

312 Zn-PS specific transport activity has been described, but ZmYS1 can transport DMA complexes

313 with $\mathrm{Zn}, \mathrm{Cu}, \mathrm{Mn}, \mathrm{Ni}$, and $\mathrm{Cd}$ when expressed in yeast (Saccharomyces cerevisiae Meyen ex

314 E.C.Hansen) and frog oocytes (Xenopus laevis) (Schaaf et al. 2004). Besides, the mutant maize

315 ys1 (defective for ZmYS1, the Fe-PS transporter) cannot absorb Zn complexes with either DM A

316 or eHM A (epi-hydroxymugineic acid) (Von Wiren et al. 1996). This suggests that Zn might share

317 the same uptake pathway as Fe in Strategy II plants under Zn deficiency. In agreement, several

318 surveys report a significant increase in PS secretion in Zn-deficient wheat (Triticum aestivum

319 L.), barley, triticale (xTriticosecale Wittm. ex A.Camus), and rye (Secale cereale L.) (Zhang et al.

320 1989; Cakmak et al. 1994; Gries et al. 1995; Cakmak et al. 1996; Erenoglu et al. 1996; Cakmak 
et al. 1998a; Cakmak et al. 1998b; Rengel 1999; Erenoglu et al. 2000; Suzuki et al. 2006), which

322

reverts to control levels within 72 hours after Zn is resupplied (Zhang et al. 1989). M oreover, many Zn-efficient varieties of wheat, barley, and rice have shown higher PS release rate during Zn-deficiency than the inefficient ones (Cakmak et al. 1994; Cakmak et al. 1996; Cakmak et al. 1998a; Rengel et al. 1998; Rengel and Römheld 2000; Erenoglu et al. 2000; Tolay et al. 2001; Widodo et al. 2010; Neelam et al. 2010; Daneshbakhsh et al. 2013). In contrast, analogous experiments found no significant difference in PS release in Zn-deficient rice, wheat, and barley (Pedler et al. 2000; Suzuki et al. 2008; Widodo et al. 2010), or between Zn-efficient and inefficient wheat and barley (Erenoglu et al. 1996; Cakmak et al. 1998b; Pedler et al. 2000). These inconsistencies in the literature might indicate that Zn-efficiency in crops is determined by various factors, including PS release by the roots and possibly others. Interestingly, in some instances when Zn-efficiency and PS release did not correlate, Zn-efficient plants still took up more $\mathrm{Zn}$ and had higher root-to-shoot translocation rates (Von Wiren et al. 1996; Cakmak et al. 1998b). It was suggested that Zn-efficient varieties might have higher rates of Zn-PS uptake and $\mathrm{Zn}$ export to the shoot, while the release rates were not necessarily increased.

A central question is if the secretion rates observed during $\mathrm{Zn}$ deficiency and the $\mathrm{Zn}$-PS complexes subsequently formed could account for the $\mathrm{Zn}$ budget of plants. The stability constant of Fe(III)-PS complexes (10 $10^{18.4}$ ) is significantly higher than that of $\mathrm{Zn}$-PS complexes $\left(10^{12.9}\right)$ (M urakami et al. 1989), which might make it difficult for the latter to form in presence of $\mathrm{Fe}(\mathrm{III})$. The amount of PS secreted during Fe-deficiency is much higher than during Zn-deficiency, up to 25 fold in rice (Suzuki et al. 2008), 23 fold in barley (Suzuki et al. 2006), and 16 fold in wheat (Tolay et al. 2001). In a recent study in wheat (cv Tamaro) grown in calcareous Fe-deficient soils, PS secretion from the roots ranged from 0.2 to $41 \mathrm{pmol}^{\mathrm{DMA} \mathrm{g}} \mathrm{g}^{-1}$ root DW s${ }^{-1}$, which is about 50 times less than solution-grown plants typically secrete (Oburger et al. 2014). It was argued that the PS release data from solution-grown plants in zero [Zn] or [Fe] might be grossly over-estimated, since these extreme conditions are not realistic in the 
347 field. In soils, at least a small amount of those metals will be available for plants, reducing the

348 need for PS release. The PS release in soil-grown wheat was strongly increased by soil 349 characteristics like salinity and low trace element availability (Oburger et al. 2014). Salinity had 350 been previously seen to increase PS release rates in solution-grown wheat (Daneshbakhsh et 351 al. 2013). To the best of our knowledge, there are no data available of PS release in $\mathrm{Zn}$ deficient soils. This information is crucial to determine if the PS make a significant contribution to $\mathrm{Zn}$ uptake, and build an accurate model of $\mathrm{Zn}$ uptake by plants in $\mathrm{Zn}$-deficient soils. Furthermore, since Fe and Zn might compete for the binding sites of PS and the uptake of the resulting complexes, the interaction between Fe and $\mathrm{Zn}$ needs to be better understood for the correct interpretation of $\mathrm{Zn}$ isotopic fractionation in $\mathrm{Zn}$-deficient graminaceous plants. In the particular case of rice, the effect of flooding and anoxia on the soil chemistry and plant physiology needs to be considered, since this crop is usually grown in inundated fields. In waterlogged soils, $\mathrm{Fe}^{2+}$ in soil solution is high while $\mathrm{Zn}$ availability is reduced by precipitation (Becker and Asch 2005). Mathematical modelling has shown that the rate of DMA release observed in $\mathrm{Zn}$-deficient rice $\left(\approx 10 \mathrm{pmol}^{\mathrm{DMA} \mathrm{g}} \mathrm{g}^{-1}\right.$ root FW $\left.\mathrm{s}^{-1}\right)$ can fully account for the $\mathrm{Zn}$ uptake observed in a Zn-deficient submerged soil (Ptashnyk et al. 2011). However, the PS release data used for the model were obtained from solution-grown rice in aerobic conditions with low $\mathrm{Fe}^{2+}$ (Suzuki et al. 2006; Widodo et al. 2010). Unfortunately, no PS release data have been obtained in conditions which simulate anaerobic soil high in $\mathrm{Fe}^{2+}$ and low $\mathrm{Zn}$. Analysis of gene expression has revealed that $\mathrm{Fe}^{2+}$ toxicity can down-regulate the expression of genes involved in PS synthesis and Fe-PS uptake in rice roots after short exposure times (three days) (Quinet et al. 2012). However, it is a short-lived effect. The expression levels are equal to the control or even higher after longer exposure times (1 to 3 weeks) (Quinet et al. 2012; M üller et al. 2015). Moreover, the stability constant of $\mathrm{Zn}-\mathrm{PS}\left(10^{12.9}\right)$ is higher than that of $\mathrm{Fe}(\mathrm{II})-\mathrm{PS}$

$371\left(10^{10.5}\right)$ (Murakami et al. 1989). It is thus possible that PS have a role in Zn-uptake by Zn372 deficient rice in waterlogged soils rich in $\mathrm{Fe}^{2+}$. An interesting feature of plants tolerant to 
373 submersion is that they can have their roots covered by an iron plaque. This is a coat of

374 precipitated Fe(III) hydroxides formed thanks to the oxygen leaked from the roots. Up to $25 \mathrm{~g}$

375 of iron plaque per $\mathrm{Kg}$ of root DW might favour $\mathrm{Zn}$ uptake in rice, whereas a higher amount

376 interferes with Zn uptake (Zhang et al. 1998). The effect of the Fe plaque is larger in plants

377 previously grown in Fe-deficient solution, and the Fe-deficient plants had a higher [Zn] in

378 shoots. It was concluded that the PS might promote $\mathrm{Zn}$ uptake in plants with iron plaque by

379 mobilizing Zn adsorbed to it.

380 Besides PS, plant roots exudate a mixture of organic acids and amino acids that enhance $\mathrm{Zn}$

381 dissolution from the soil by lowering the $\mathrm{pH}$ around the roots and binding to $\mathrm{Zn}$ (Rasouli-

382 Sadaghiani et al. 2011). This strategy is also present in plant families that do not synthesize PS,

383 where $\mathrm{Zn}$ and other metals can be taken up in form of complexes (Degryse et al. 2007).

384 Furthermore, root exudates solubilize $\mathrm{Zn}$ from $\mathrm{Zn}$-containing minerals like smithsonite $\left(\mathrm{ZnCO}_{3}\right)$

385 (Houben and Sonnet 2012). For example, tomato seedlings were grown in resin-buffered

386 solution at two external $[\mathrm{Zn}]\left(10^{-6}\right.$ or $\left.1.5 \times 10^{-8} \mathrm{M}\right)$ and two pot sizes, to manipulate the

387 concentration of root exudates (Smolders et al. 2013). The highest [Zn] in the solution after

388 plant growth was recorded in the experimental conditions that most favoured the

389 accumulation of root exudates in the solution (low $\mathrm{Zn}$ and small pot). This suggested that root

390 exudates can also have an important role in mobilizing $\mathrm{Zn}$ in dicots. Besides, the shoots at $10^{-6}$

391 M Zn were enriched in light isotopes (-0.52\%o to $-0.56 \%$ ). By contrast, plants grown at $1.5 \times 10^{-8}$

$392 \mathrm{M}$ had a similar isotopic composition as the roots $\left(\Delta^{66} \mathrm{Zn}_{\text {shoot-root }}=0.06 \%\right.$ to $-0.09 \%$ ) (Smolders

393 et al. 2013). It was hypothesized that at high Zn supply uptake was dominated by the

394 facilitated diffusion of free $\mathrm{Zn}^{2+}$, which favours ${ }^{64} \mathrm{Zn}$, whereas at low $\mathrm{Zn}$ supply most of the $\mathrm{Zn}$

395 was taken up as Zn complexes. The heavier isotopes accumulate in the complexes because

396 they form stronger bonds. The resulting complexes do not undergo isotopic fractionation

397 during transport because the relative difference of mass (isotope vs complex) is too small. Zinc

398 is preferentially taken up by plants as free $\mathrm{Zn}^{+2}$ (Marschner and Marschner 1995). However, 
399 the uptake of entire Zn complexes has been reported in barley, potato (Solanum tuberosum

400 L.), Brassica juncea (L.) Czern., and Lupinus albus L. (Collins et al. 2002). Specific transporters

401 like AtHMA2 or members of the YSL (Yellow Stripe-like) family might facilitate the uptake of Zn

402 complexes with ligands in the root exudates, but direct evidence is still missing (Schaaf et al.

403 2004; Eren and Argüello 2004).

404 Plants adapted to low-phosphorus soils can emit large amounts of carboxylates in response to 405 phosphorus (P) deficiency (Gerke 2015). These carboxylates can increase the availability of Zn 406 and other metals from the rhizosphere (Duffner et al. 2012; Lambers et al. 2015). Zinc content

407 in the leaves of Hakea prostrata R.Br. increased with the development of cluster roots, which 408 was attributed to the high release of carboxylates typical of these type of roots (Shane and 409 Lambers 2005). In the same study, Zn concentration in leaves decreased with increasing P 410 availability. Similar antagonistic interaction between $\mathrm{Zn}$ and $\mathrm{P}$ has been repeatedly observed in 411 the literature (Imran et al. 2016; Zhang et al. 2016). This suggests that P availability could 412 affect the $\mathrm{Zn}$ isotopic composition of the plant by increasing the proportion of $\mathrm{Zn}$ taken up in 413 form of Zn complexes with OA. This interesting possibility has not been explored so far, and 414 would be useful for the study of Zn-P interaction.

Isotope fractionation of $\mathrm{Zn}$ during transport to the aerial parts

417 Zinc transfer from the root to the stem

418 The $\Delta^{66} \mathrm{Zn}_{\text {shoot-root }}$ of $\mathrm{Zn}$-sufficient hydroponically grown rice, tomato, and wheat is in the range -0.56 to $-0.25 \%$ (Weiss et al. 2005; Jouvin et al. 2012; Smolders et al. 2013). This shift in favour of the light isotopes has been attributed to $\mathrm{Zn}$ uptake facilitated by transporters at the membrane of the root cells, as discussed in section 4.2. However, in soil-grown plants the stem was sometimes isotopically heavier than the roots $\left(\Delta^{66} \mathrm{Z} \mathrm{n}_{\text {stem-root }}\right.$ from -0.33 to $0.25 \%$ ) (Viers et 423 al. 2007; M oynier et al. 2009; Viers et al. 2015). This could be explained by plants taking up a 424 greater proportion of $\mathrm{Zn}$-complexes due to a lower availability of $\mathrm{Zn}$ in the natural 
environment. However, we must also pay attention to the different sampling methods used. In

426 the hydroponic studies (Weiss et al. 2005; J ouvin et al. 2012; Smolders et al. 2013) all the aerial

427 parts were sampled together, whereas in the field studies (Viers et al. 2007; Moynier et al.

428 2009; Viers et al. 2015) stems and leaves were analyzed separately. The contribution of the

429 leaves might then explain the shift between the solution-grown and the soil-grown plants.

430 Besides, a number of processes take place during $\mathrm{Zn}$ transfer from the root symplast to the

431 aerial parts that are likely to discriminate $\mathrm{Zn}$ isotopes. In the intra-cellular fluid (cytosol) the pH

432 is close to neutral (7.2-7.5), and $\mathrm{Zn}^{2+}$ will be kept at a very low concentration (in the pM

433 range)(Maret 2015) to avoid precipitation and misplaced binding. There are several low-weight

434 molecules that have been proposed as important $\mathrm{Zn}$ ligands in the cytosol, such as

435 nicotinamine (NA), histidine, organic acids, and small peptides (for a review, see Sinclair and

436 Krämer 2012). Of these, the non proteinogenic amino acid NA is considered the main Zn ligand

437 in the cytosol, and a key factor in enhancing Zn mobility in the symplast (Clemens et al. 2013).

438 The fractionation of $\mathrm{Zn}$ isotopes during the formation of $\mathrm{Zn}$ complexes with NA has not been

439 explored. However, ab initio calculations have shown that the partitioning of heavy isotopes

440 between citrates, malates, phosphates, histidine, and other Zn species can account for part of

441 the isotopic fractionation observed in plants, which will be further discussed in section 6.2

442 (Fujii and Albarède 2012; Fujii et al. 2014). The computational studies suggested that heavy

443 isotopes tend to bind to oxygen donors, while light isotopes accumulate in Zn complexes with

444 sulphur donors, and Zn complexes with nitrogen donors would be between the two or

445 isotopically heavier than with oxygen donors (Fujii et al. 2014). Recent experimental evidence

446 has confirmed that the heavy isotopes accumulate in Zn complexes with DM A, and structurally

447 similar ligands (M arkovic et al. 2016). Another potential source of isotope discrimination is Zn

448 sequestration in the vacuoles. The activity of the vacuolar transporters regulates the amount

449 of $\mathrm{Zn}$ in the cytosol available for translocation by either increasing or decreasing the amount of

450 Zn sequestered in the vacuoles. Several studies conclude that MTP1 and MTP3 (Metal 
451 Tolerance Proteins) facilitate the efflux of $\mathrm{Zn}^{2+}$ from the cytosol into the vacuole (reviewed by

452 Ricachenevsky et al. 2013). The vacuole has an acidic pH around 5.2 (Shen et al. 2013) and Zn

453 can stay soluble as $\mathrm{Zn}^{2+}$. Similarly, AtZIF1 is a tonoplast transporter that carries $\mathrm{Zn}$ complexes

454 with NA into the vacuoles (Haydon et al. 2012). Transporter AtNRAM P4 facilitates Zn influx

455 from the vacuole back into the cytoplasm (Lanquar et al. 2010). Additionally, $\mathrm{Zn}^{2+}$ can diffuse

456 from one cell to another across the plasmodesmata, small openings in the cell walls that allow

457 the cytoplasm of adjacent cells to communicate. This is a kinetically controlled process that will

458 favour the light isotopes (Criss 1999).

459 To reach the shoot, $\mathrm{Zn}$ needs to leave the root symplast and enter the xylem, a conductive 460 tissue formed by the walls of dead cells containing no cytoplasm. Transporters HMA2 and 461 HMA4 are plasma membrane transporters of the HMA family (Heavy Metal ATPases) 462 expressed in the vasculature of the root, and are thought to export $\mathrm{Zn}$ from the adjacent cells 463 to the xylem in arabidopsis (Eren and Argüello 2004). Of these, HM A2 transports Zn bound to a 464 ligand while HM A4 transports $\mathrm{Zn}^{2+}$. The xylem sap is considered an acidic environment with $\mathrm{pH}$ 465 around 5.5 where $\mathrm{Zn}^{2+}$ could stay in solution, although it can be alkalinized in response to 466 drought, flooding, bicarbonates, nutrients, light, change of season, daily rhythms, and disease 467 (Wilkinson, Janet E. Corlett, Ludovic Oger et al. 1998). Little is known about how these 468 fluctuations affect $\mathrm{Zn}$ xylem loading and forms in the xylem sap. In the xylem sap of strategy I 469 plants $\mathrm{Zn}$ is predominantly transported as $\mathrm{Zn}^{2+}$ with the remaining fraction bound to organic acids (Salt et al. 1999; Monsant et al. 2011; Lu et al. 2014). The aminoacids histidine (Kozhevnikova et al. 2014) and NA (Cornu et al. 2015) have also been proposed a role in

472 Zn-binding in the xylem. In strategy II plants, Zn-DM A complexes have been identified in root 473 extracts of Fe-deficient wheat (Xuan et al. 2006), and in the shoots of japonica rice (Tsednee et 474 al. 2016), which suggests that Zn could be transported up the xylem as Zn-PS complexes. All of 475 these steps might contribute to the isotope ratios of roots and shoots. 
478 The few experiments that analysed leaves separately found generally isotopically lighter $\mathrm{Zn}$

479 compared to the stems ( $\Delta^{66} \mathrm{Zn}_{\text {leaves-stem }}-1.67$ to $0.10 \%$ )(Viers et al. 2007; M oynier et al. 2009;

480 Caldelas et al. 2011; Viers et al. 2015). Furthermore, the leaves of various plant species were 481 increasingly depleted in ${ }^{66} \mathrm{Zn}$ the further they were from the root (Fig. 3). First, tree leaves collected from a pristine tropical drainage basin were recorded as isotopically lighter $483\left(\delta^{66} \mathrm{Zn}_{\text {leaves }}-0.03 \%\right.$ to $\left.-0.91 \%\right)$ than the leaves of the herbaceous species in the same area (0.26 to $0.63 \%$ ) (Viers et al. 2007). The observations by Viers et al. 2007 were confirmed in bamboo leaves collected at various heights $(20,50$, and $80 \mathrm{~cm})$, which showed a progressive decrease of $\delta^{66} \mathrm{Zn}$ with distance $(-0.19 \%$, $-0.32 \%$, and $-0.55 \%$ respectively)(M oynier et al. 2009). Both studies proposed that the negative $\delta^{66} \mathrm{Zn}$ of the leaves could be explained as the sum of two processes: i) Faster transport of ${ }^{64} \mathrm{Zn}$ across the plasma membranes, throughout $\mathrm{Zn}$ transfer from the roots to the leaves, and ii) preferential unload of ${ }^{66} \mathrm{Zn}$ from the xylem sap into the adjacent cells by low-affinity transporters, leaving the xylem solution progressively enriched in ${ }^{64} \mathrm{Zn}$. Zinc binding to the cell walls lining the xylem vessels might also occur,

492 favouring the depletion of heavy isotopes in the xylem sap via ion exchange. A similar trend was observed in reeds, where a fractionation of up to $-0.44 \%$ was measured between leaves sampled at 5 and $100 \mathrm{~cm}$ (Caldelas et al. 2011). The extent of $\mathrm{Zn}$ fractionation with height was very consistent: $-0.005 \% \mathrm{~cm}^{-1}$ in reed (Caldelas et al. 2011) and $-0.006 \% \mathrm{~cm}^{-1}$ in bamboo (M oynier et al. 2009).

497 To leave the xylem and enter the leaf symplast $\mathrm{Zn}$ must first cross the membranes of the companion cells, a step mediated by transporters yet to be characterized. Membrane transporters AtIRT3 and OsZIP4 are expressed in the vasculature of the leaves and might

500 facilitate both xylem unloading and phloem loading of $\mathrm{Zn}^{2+}$ (Ishimaru et al. 2005; Lin et al. 501 2009). The xylem unloading of $\mathrm{Zn}^{2+}$ could contribute to the enrichment of light isotopes 502 observed in the leaves relative to the stem. The xylem loading, transport, and unloading of $\mathrm{Zn}$ 
503 in form of $\mathrm{Zn}$-NA or other $\mathrm{Zn}$ complexes is not expected to discriminate $\mathrm{Zn}$ isotopes.

504 Alternatively, $\mathrm{Zn}$ can be remobilized from older tissues and transported to the leaves via the

505 phloem. Excess Zn is stored in the vacuoles of the leaves in form of $\mathrm{Zn}$ complexes with citrate,

506 malate, or NA (Aucour et al. 2011; Tang et al. 2012). The formation of those Zn complexes

507 would likely favour the accumulation of heavy $\mathrm{Zn}$ isotopes in the complexes in the vacuole,

508 leaving an isotopically lighter $\mathrm{Zn}^{2+}$ pool available for transport in the cytosol. Tonoplast

509 transporters NRAM P3 and NRAMP4 in Arabidopsis facilitate $\mathrm{Zn}^{2+}$ efflux from the vacuole and

510 are expressed in leaves (Lanquar et al. 2010). Znc facilitated diffusion across the tonoplast

511 should be faster for ${ }^{64} \mathrm{Zn}$, which would contribute further to the accumulation of light isotopes

512 in the $\mathrm{Zn}^{2+}$ pool available for transport. However, the $\mathrm{pH}$ in the cytosol is close to neutral

513 (7.2-7.5), while the phloem sap is slightly alkaline (7.3-8.5) (Dinant et al. 2010). In these

514 conditions Zn must bind to an intracellular ligand to stay soluble, probably NA (von Wiren et al.

515 1999; Nishiyama et al. 2012). This would probably lead to the accumulation of ${ }^{66} \mathrm{Zn}$ in the

516 Zn-NA complexes, although this has not been tested. Metal loading from the cytosol of the

517 companion cells into the phloem is likely facilitated by plasma membrane transporters of the

518 YSL family, which transport metal complexes with NA. Transporters OsYSL2, AtYSL1, and

519 AtYSL3 transport NA complexes with Fe and other metals and are expressed in the vasculature

520 of the leaves (Koike et al. 2004; Chu et al. 2010). Analogous YSL transporters might be involved

521 in $\mathrm{Zn}$ loading from the phloem, but they have not been identified yet. In the phloem, $\mathrm{Zn}$ is

522 predominantly found as Zn-NA complexes (Nishiyama et al. 2012; Hazama et al. 2015). The

523 mechanisms of $\mathrm{Zn}$ unloading from the phloem at the leaves are poorly known. The phloem

524 loading, transport, and unloading of $\mathrm{Zn}$ in form of $\mathrm{Zn}$-NA complexes is not expected to

525 discriminate $\mathrm{Zn}$ isotopes. Taking all the evidence together, it is yet not clear if $\mathrm{Zn}$

526 remobilization from older leaves to young ones could account for the enrichment of light

527 isotopes in leaves with height. To advance our understanding of $\mathrm{Zn}$ isotopic fractionation from

528 the stem to the leaves, and from older to younger leaves, we need to first determine the $\mathrm{Zn}$ 
529 forms in all the relevant Zn pools in the leaves, and to characterize the transporters that move

$530 \quad$ Zn between those pools.

531

532 Zinc allocation to the seeds

533 Evidence of isotopic fractionation during $\mathrm{Zn}$ transfer to the seeds is scarce. A recent study

534 found that in soil-grown rice the seeds were isotopically lighter than the shoots $\left(\Delta^{66} \mathrm{Zn}\right.$ seed-

535 shoot -0.8 to $-0.7 \%$ )(Arnold et al. 2015). This was attributed to $\mathrm{Zn}$ remobilization from the stem

536 during grain filling. However, the specific causes for this enrichment of the light isotopes are

537 not clear, because there is insufficient information of the molecular mechanisms and $\mathrm{Zn}$

538 species involved in $\mathrm{Zn}$ transfer to the seeds in rice. Zinc in the rice grain is delivered via two

539 routes: i) phloem loading after remobilization from the leaves and stems (as discussed above),

540 and ii) direct xylem-to-phloem transfer in the stem and the nodes of the seed panicle, the

541 loosely-branched cluster of seeds (Yoneyama et al. 2010; Wu et al. 2010). The plasmatic

542 membrane transporter OsHMA2 is highly expressed at the nodes, and is believed to be

543 involved in the xylem-to-phloem transfer of Zn to the panicle (Yamaji et al. 2013). Tonoplast

544 transporters OsVIT1 and OsVIT2 (Vacuolar Iron Transporters) facilitate the influx of Zn into the

545 vacuole and are mainly expressed in the flag leaves, suggesting a primary role in the regulation

546 of $\mathrm{Zn}$ export to the seeds (Zhang et al. 2012). The activity of these transporters could

547 contribute to the observed enrichment of the light isotopes in seeds relative to shoots in rice,

548 but additional fractionation processes likely contribute. To allocate $\mathrm{Zn}$ to the developing seeds,

549 Zn must exit the phloem and cross a series of species-specific apoplastic barriers between the

550 maternal transfer cells, specialized in the transfer of solutes, and the endosperm of the seed,

551 the tissue that surrounds and nourishes the embryo (Olsen and Palmgren 2014). These

552 apoplastic barriers and the processes that control Zn transport across them are poorly known.

553 In barley, a detailed model of $\mathrm{Zn}$ trafficking to the seed has been proposed based on RNA

554 expression data from seed tissues (Tauris et al. 2009), which suggests that Zn would enter the 
maternal transfer cells from the phloem in form of Zn-NA complexes. In the cytosol of the

556 transfer cells Zn appears to be in form of Zn-NA or Zn-PS complexes, as indicated by the high

557 expression of two NA synthases (NAS5-2 and NAS9), and one NA aminotransferase (NAATB,

558 that converts NA into DMA) (Tauris et al. 2009). The symplastic movement of Zn-NA complexes

559 from the phloem into the transfer cells would not cause any isotopic fractionation, whereas

560 the formation of $\mathrm{Zn}$-complexes in the cytosol of the transfer cells would lead to the

561 accumulation of heavy isotopes in the complexes relative to the $\mathrm{Zn}^{2+}$ fraction. The vacuolar transporters M TP1, M TPc4, VIT1-1, and CAX1a,b are highly expressed in the transfer cells, and thought to promote $\mathrm{Zn}^{2+}$ flow into the vacuole (Tauris et al. 2009). Transporting $\mathrm{Zn}^{2+}$ into the vacuole would likely result in the accumulation of light $\mathrm{Zn}$ isotopes in the vacuole relative to the cytosol. During grain filling, $\mathrm{Zn}^{2+}$ stored in the vacuole of the transfer cells would be remobilized by the vacuolar transporter NRAMP3 (Tauris et al. 2009). This transporter might

567 further enrich the light isotopes in the remobilized fraction relative to the vacuole. Thus $\mathrm{Zn}$

568 storage and remobilization might cause the enrichment of light isotopes in the $\mathrm{Zn}^{2+}$ fraction

569 available for export to the seed relative to the Zn-NA fraction in the cytosol. Zinc efflux from

570 the cytosol of the transfer cells would be facilitated by plasma membrane transporters HM A2,

5714 , and 8, which are proposed to pump $\mathrm{Zn}^{2+}$ out to the endosperm cavity (Tauris et al. 2009) and might cause further enrichment of the light isotopes in the $\mathrm{Zn}$ pool allocated to the seed.

573 Tauris and co-workers proposed that $\mathrm{Zn}$ would be in form of $\mathrm{Zn}^{2+}$ or $\mathrm{Zn}$-complexes with NA or

574 DMA in the endosperm cavity, while $\mathrm{Zn}^{2+}$ would diffuse towards the seed, a

575 kinetically-controlled process that favours the light isotopes. In the aleurone (the outermost 576 layer of the endosperm) and the embryo, $\mathrm{Zn}^{2+}$ uptake would be facilitated by transporters of 577 the ZIP family, while YSL6, 9, and 12 would do the same with the Zn-complexes. Zinc efflux 578 from the seed back to the endosperm cavity was probably minimal, since the HMA 579 transporters involved in Zn efflux from the cytosol back into the apoplast showed much lower 580 transcription rates in the aleurone, endosperm, and embryo than in the maternal transfer cells 
581 (Tauris et al. 2009). This suggests that Zn movement and compartmentalization within the

582 seed after Zn uptake in the aleurone would not substantially add to the fractionation of $\mathrm{Zn}$

583 isotopes between the seed and the shoot.

584 In summary, it appears that the enrichment of light isotopes in the seeds relative to the shoots could originate from $\mathrm{Zn}^{2+}$ storage in the vacuoles of the transfer cells, efflux from transfer cells, diffusion in the endosperm cavity, and uptake by aleurone cells. Additionally, mechanisms that lead to the enrichment of light isotopes in the phloem sap relative to the bulk shoot, like Zn remobilization from the older tissues or direct xylem-to-phloem Zn transfer could contribute to make seeds isotopically lighter than the shoots. The $\delta^{66} \mathrm{Zn}$ of the grain might prove an interesting tool for the development of $\mathrm{Zn}$ biofortification in crops, which could help us identify the key mechanisms involved in $\mathrm{Zn}$ allocation into the seed. However, there is a pressing need for more isotope data from seeds and a better knowledge of the molecular mechanisms behind $\mathrm{Zn}$ allocation to the seed and the $\mathrm{Zn}$ forms in the different reservoirs.

\section{Fractionation of $\mathrm{Zn}$ isotopes associated with plants response to $\mathrm{Zn}$ excess}

596 Accumulation in the roots of Zn-tolerant plants

597 Tolerant plants are those that can grow and develop when [ $\mathrm{Zn}]$ in the environment would usually be deleterious. In tolerant plants exposed to an excessive amount of $\mathrm{Zn}$ in the environment, roots play an important role in $\mathrm{Zn}$ detoxification and sequestration to protect sensitive photosynthetic tissue. The response of tolerant plants to high $\mathrm{Zn}$ levels can cause significant changes in the distribution of $\mathrm{Zn}$ isotopes across the plant organs in some species. In reed (Phragmites australis [Cav.] Trin. ex Steud) grown hydroponically with sufficient Zn supply $\left(3 \times 10^{-6} \mathrm{M}\right)$ the roots, rhizomes, and shoots were similarly enriched in heavy isotopes relative to 604 the growth solution $(\sim 0.2 \%$ ) (Caldelas et al. 2011)(Fig. 4a). By contrast, the addition of $\mathrm{Zn}$ in an excessive amount $\left(2 \times 10^{-3} \mathrm{M}\right)$ caused further enrichment of the heavy isotopes in roots relative to the growth solution ( $\Delta^{66} \mathrm{Zn}$ root-solution $=0.47 \%$ ) and relative to the stems $\left(\Delta^{66} Z n_{\text {stem-root }}=0.84\right.$ 
607 to $-0.94 \%$ o). The magnitude of both isotopic effects was larger than reported for

608 hydroponically grown crops $\left(\Delta^{66} \mathrm{Zn}_{\text {root-solution }}-0.02\right.$ to $0.16 \%$, and $\Delta^{66} \mathrm{Zn}_{\text {shoot-root }}-0.25$ 609 to $-0.56 \%$ )(Weiss et al. 2005; Jouvin et al. 2012; Smolders et al. 2013). Excess Zn can 610 precipitate with insoluble phosphates or silicates at the root epidermis, the intercellular 611 spaces, and the cell walls of the roots, a process termed biomineralization that might reduce 612 Zn influx into the symplast (Neumann and zur Nieden 2001; Straczek et al. 2008; Medas et al. 613 2015; De Giudici et al. 2015). In tobacco, Zn binds to the carboxyl and hydroxyl groups of 614 pectin and to the hydroxyl groups of cellulose in the cell walls of roots (Straczek et al. 2008).

615 The composition of the cell walls changes in response to excess $\mathrm{Zn}$, modifying its permeability, 616 binding capacity, and affinity to enhance Zn tolerance (Lin and Aarts 2012). Inside the cell, Zn 617 binds to various ligands to limit its interaction with sensitive cellular components. 618 Nicotinamine forms complexes with $\mathrm{Zn}$ that are then sequestered in the vacuoles of the root 619 cells (Trampczynska et al. 2010; Haydon et al. 2012). Phytochelatins (PC) are small peptides 620 synthesized from gluthathione that bind to $\mathrm{Zn}$ and have a role in $\mathrm{Zn}$ tolerance and 621 accumulation in the roots (Tennstedt et al. 2009). Free $\mathrm{Zn}^{2+}$ and $\mathrm{Zn}$-ligand complexes are 622 compartmentalized in the vacuole so they cannot interfere with the cell metabolism. This is 623 achieved by means of specific vacuolar transporters. Several tonoplast $\mathrm{Zn}$ transporters 624 involved in Zn sequestration in the vacuoles of the root cells have been described, belonging to 625 the protein families M TP, HM A, and ZIF (Zinc-Induced Facilitators)(reviewed by Peng and Gong 626 2014). Arabidopsis AtM TP1 and AtM TP3, OsM TP1 in rice, and HvM TP1 in barley are expressed 627 in the roots, facilitate $\mathrm{Zn}$ efflux to the vacuole, and have a role in $\mathrm{Zn}$ tolerance (Kobae et al. 628 2004; Arrivault et al. 2006; Podar et al. 2012; M enguer et al. 2013). A similar function has been 629 attributed to AtHM A3 and AtZIF2 in arabidopsis, which are mainly expressed in the roots and 630 are involved in Zn tolerance (M orel et al. 2009; Remy et al. 2014). Finally, AtZIF1 is a tonoplast 631 transporter in arabidopsis that carries Zn-NA complexes into the vacuoles and is mostly 632 expressed in the roots (Haydon et al. 2012). 
633 The individual contribution of each of the mechanisms of $\mathrm{Zn}$ sequestration in the root 634 discussed above to the partitioning of $\mathrm{Zn}$ isotopes in plants is not yet clear. In Phalaris 635 arundinacea L. grown in soil receiving Zn-polluted stormwater, around $30-40 \%$ of the $\mathrm{Zn}$ in 636 roots was present in tetrahedral coordination, which may correspond to apoplasmic $\mathrm{Zn}$ binding 637 to the cell walls (Aucour et al. 2015)(Fig. 4a). The rest of the $\mathrm{Zn}$ fraction was coordinated in an 638 octahedral structure, probably binding to ligands like organic acids and sequestered in the 639 vacuoles. The $\Delta^{66} \mathrm{Zn}_{\text {shoot-root }}$ in this study was $-0.83 \%$, very similar to previous results in $\mathrm{P}$. 640 australis $\left(\Delta^{66} \mathrm{Zn}_{\text {shoot-root }}=0.84\right.$ to $-0.94 \%$ ) (Caldelas et al. 2011 ), and to recent data in Noccaea 641 caerulescens (J.Presl \& C.Presl) and Thlaspi arvense L. $\left(\Delta^{66} \mathrm{Zn}_{\text {shoot-root }}=0.79 \%\right.$ in both species) 642 (Tang et al. 2016). In the later study $\mathrm{Zn}$ in roots was separated into symplastic and apoplastic 643 fractions by successive extractions. Most of $\mathrm{Zn}$ in roots was in the symplastic fraction (69 to $64493 \%$, and in both species the proportion of apoplastic Zn increased around 20\% at high [Zn] 645 (50 $\mu \mathrm{M}$ for $\mathrm{N}$. caerulescens and $5 \mu \mathrm{M}$ for $\mathrm{T}$. arvense, in accord with their different tolerance). 646 This evidence suggests a common pattern of $\mathrm{Zn}$ exclusion during $\mathrm{Zn}$ excess for $\mathrm{P}$. australis, $\mathrm{P}$. 647 arundinacea, N. caerulescens and T. arvense, where isotopically heavy $\mathrm{Zn}$ would be 648 sequestered in the apoplast. However, not all Zn-tolerant species show enhanced ${ }^{66} \mathrm{Zn}$ 649 accumulation in the roots when exposed to high $\mathrm{Zn}$ levels. For instance, Silene vulgaris 650 ([M oench.] Garcke.) growing in a contaminated soil showed no significant shift between soil, 651 roots, and shoot (Tang et al. 2012)(Fig. 4b). Furthermore, ${ }^{66} \mathrm{Zn}$ was enriched in the roots of the 652 tolerant grass Agrostis capillaris (L.) grown in two different technosols compared to soils and 653 to shoots $\left(\Delta^{66} Z n_{\text {root-solution }}=0.07-0.19 \%, \Delta^{66} Z n_{\text {shoot-root }}=0.24\right.$ to $-0.40 \%$ ) (Houben et al. 2014$)$ (Fig. $6544 \mathrm{~d}$ ), but the magnitude of the fractionation was comparable to that of non-tolerant plants. The 655 same seems to hold for rapeseed (Brassica napus L.) and rye grass (Lolium multiflorum L.) 656 grown in pots containing three multi-polluted soils $\left(\Delta^{66} \mathrm{Zn}_{\text {root-solution }}=0.05-0.20 \%\right.$, $657 \Delta^{66} \mathrm{Zn}_{\text {shoot-root }}=0.04$ to $-0.39 \%$ )(Couder et al. 2015). 
658 Besides the sequestration of $\mathrm{Zn}$ in the roots, plants display other responses to $\mathrm{Zn}$ excess that

659 possibly discriminate $\mathrm{Zn}$ isotopes. Both Arabidopsis thaliana (L) and Arabidopsis halleri (L.) 660 secrete NA to the rhizosphere, where it forms Zn-NA complexes, and A. halleri increases NA 661 secretion when exposed to high Zn levels in the environment (Tsednee et al. 2014). In the 662 same study, [Zn] in the roots of $A$. thaliana decreased by up to $60 \%$ when $50 \mu \mathrm{M}$ NA was 663 added to the soil, indicating that the $\mathrm{Zn}$-NA complexes were not taken up by the root cells. It 664 was concluded that plants secrete NA to the rhizosphere to reduce Zn bioavailability in the soil. 665 Moreover, the secretion of NA increased in A. halleri in response to excess $\mathrm{Zn}$ To illustrate the 666 impact of root exudates on the isotopic composition of the soil solution, Agrostis capillaris was 667 grown in columns filled with two technosols and compared with controls without plant cover 668 (Houben et al. 2014). The columns were irrigated with nutrient solution in excess and allowed 669 to drain, and the resulting leachates were collected and analyzed. Without plants, the 670 leachates were isotopically lighter than the soil $\left(\Delta^{66} \mathrm{Zn}_{\text {leachates-soil }}=0.12\right.$ to $\left.-0.21 \%\right)$, meaning 671 that the leaching of free $\mathrm{Zn}^{2+}$ from the soil removed the light isotopes. By contrast, in columns 672 planted with A. capillaris the leachates were isotopically heavier than the soil $\left(\Delta^{66} \mathrm{Zn}\right.$ leaches-soil $673=0.14$ to $0.04 \%$ ), with up to 4 times more $\mathrm{Zn}$. This was attributed to the mobilization of $\mathrm{Zn}$ 674 from an isotopically heavier pool in the soil facilitated by the root exudates. Further work is needed to determine whether the mobilized $\mathrm{Zn}$ is then taken up by the A. capillaris or remains in the soil. On top of stimulating the secretion of root exudates, an excessive $\mathrm{Zn}$ supply

677 modifies the activity of some $\mathrm{Zn}$ transporters in the membrane of the root cells, which could have an impact in Zn isotope partitioning. High Zn levels inhibit the activity of plasma membrane transporters like AtIRT3 in arabidopsis, involved in Zn uptake by the roots (Lin et al. 2009). The $Z n$ efflux transporter AtPCR2 in arabidopsis exports excess Zn from the cytoplasm

681 to outside the cell, and its expression in yeast is increased at high Zn levels (Song et al. 2010).

682 Another process contributing to the accumulation of ${ }^{64} \mathrm{Zn}$ in the aerial parts of $\mathrm{Zn}$-tolerant 683 plants under $\mathrm{Zn}$ stress has been suggested in B. napus and L. multiflorum grown in three 
684 different soils with high $\mathrm{Zn}$ (Couder et al. 2015). A significant negative correlation $\left(\mathrm{R}^{2}=0.83\right.$, $685 \mathrm{p}=0.01$ ) was found between the $\Delta^{66} \mathrm{Zn}_{\text {shoot-root }}$ and the transpiration per total dry biomass. The 686 authors proposed that bulk mass flow driven by transpiration controlled $\mathrm{Zn}$ flux from the soil 687 into the plant under high $\mathrm{Zn}$ supply. However, the precise mechanism by which the 688 fractionation could be generated during the convective transport of $\mathrm{Zn}$ up the shoot remains obscure. The preferential binding of ${ }^{66} \mathrm{Zn}$ to the cell walls of the xylem vessels might cause this effect, but experimental evidence is missing. Besides, it has been suggested that $\mathrm{Zn}$ might enter the root xylem via the apoplastic pathway (White et al. 2002). Using literature data for N. caerulescens during high Zn supply (Lasat et al. 1996; Pence et al. 2000; Lombi et al. 2001), White and coworkers argue that $\mathrm{Zn}$ influx to the cells is smaller than $\mathrm{Zn}$ flux to the xylem, and insufficient to account for the $\mathrm{Zn}$ content of the shoots (White et al. 2002). A better understanding of plants response to $\mathrm{Zn}$ excess is crucial to discuss the distribution of $\mathrm{Zn}$ isotopes associated with it and to identify the predominant mechanisms.

697

Increased uptake and sequestration in the aerial parts of hyperaccumulators

699 Some soils are naturally high in Zn due to the composition of the parent rock (e.g. calamine or serpentine soils) (Kazakou et al. 2010; Escarré et al. 2010), and plants growing on them have adapted to these conditions. These metallicolous plants tolerate $\mathrm{Zn}$ levels that would cause death in other plants, and sometimes display unique hyperaccumulation traits: an increased rate of $\mathrm{Zn}$ uptake, a more efficient root-to-shoot translocation, and a higher sequestration capacity in the leaves $\left(>3,000 \mu \mathrm{g} \mathrm{Zn} \mathrm{g}^{-1}\right.$ shoot dry matter) without showing any toxicity symptoms (Lasat et al. 2000; Broadley et al. 2007). In these plants, Zn is compartmentalized in the leaf cell walls and vacuoles (Küpper et al. 1999). The Zn-hyperaccumulator Arabidopsis halleri and the non-accumulator Arabidopsis petraea (A. lyrata subsp. petraea [L.] O'Kane \& Al-Shehbaz) were grown hydroponically to compare the partitioning of $\mathrm{Zn}$ isotopes under $\mathrm{Zn}$ excess $\left(10^{-5} \mathrm{M}\right)$ (Aucour et al. 2011)(Fig. 4c). The heavier Zn isotopes were enriched in the roots 

of A. halleri compared with the solution (10 or $250 \mu \mathrm{M} \mathrm{Zn,} \Delta^{66} \mathrm{Zn}_{\text {root-solution }}=0.4-0.8 \%$ ) and the

711 shoots $\left(\Delta^{66} \mathrm{Zn}_{\text {shoot-root }}=0.7 \%\right.$ ), in line with results obtained for $\mathrm{P}$. australis (Caldelas et al. 2011).

712 By contrast, the roots of the related non-accumulator $A$. petraea had a similar $\delta^{66} \mathrm{Zn}$ as the 713 solution (Aucour et al. 2011). The enrichment of heavier $\mathrm{Zn}$ isotopes in the roots of A. halleri 714 relative to the roots of $A$. petraea was explained as the result of $\mathrm{Zn}$ storage in the vacuoles of 715 the root cells in form of Zn-phosphates (Aucour et al. 2011). Previous spectroscopic work had revealed that in $\mathrm{A}$. halleri $\mathrm{Zn}$ binds mostly to phosphates in the roots, and to citrate or malate

717 in the shoots (Sarret et al. 2002). Using ab initio calculations, Fujii and Albarède compared the $\delta^{66} \mathrm{Zn}$ of those three $\mathrm{Zn}$ species at total concentrations of $0.05 \mathrm{M}(\mathrm{Zn}), 0.01 \mathrm{M}$ (citrate and malate), and $1 \mathrm{M}$ (phosphate). At pH around neutral, Zn-phosphates were expected to enrich isotopically heavier $\mathrm{Zn}$ with respect to the solution, whilst $\mathrm{Zn}$-malates and $\mathrm{Zn}$-citrates would both concentrate light isotopes relative to the solution (Fujii and Albarède 2012). The $\Delta^{66} \mathrm{Zn}$ between $\mathrm{Zn}$-citrates (or Zn-malates) and $\mathrm{Zn}$-phosphates would be around -0.8 to $-0.9 \%$, consistent with the $\Delta^{66} \mathrm{Zn}_{\text {shoot-root }}$ of A. halleri $(-0.7 \%)$ and P. australis $(-0.8$ to $-0.9 \%)$ (Aucour et al. 2011; Caldelas et al. 2011). By contrast, at pH below 5 all three Zn complexes would have a similar isotopic composition as the solution (Fujii and Albarède 2012), in agreement with the roots of A. petraea having a similar $\delta^{66} \mathrm{Zn}$ as the source (Aucour et al. 2011; Tang et al. 2012). Fujii and Albarède suggested that $\mathrm{A}$. halleri might maintain the $\mathrm{pH}$ of the root cells around neutral to promote $\mathrm{Zn}$ complexation with phosphates as a tolerance mechanism, which would cause most of the heavy enrichment of the roots relative to the soil in this species (Fujii and Albarède 2012). The predominant Zn species in P. australis roots and shoots remain elusive, but the distribution of $\mathrm{Zn}$ isotopes is similar to that of $A$. halleri. This suggests that $\mathrm{Zn}$ complexation with phosphate in the roots could be a key tolerance mechanism in P. australis, which is not a hyperaccumulator species.

734 Compared with the plant-available $\mathrm{Zn}$ of the soil, ${ }^{66} \mathrm{Zn}$ was enriched in the roots of the hyperaccumulator N. caerulescens collected from a Zn-contaminated soil, a serpentine soil, 
and a non-metalliferous soil $(0.40-0.72 \%$ )(Tang et al. 2012)(Fig. 4b). Analysis of the $\mathrm{Zn}$

737 speciation in N. caerulescens has shown that in the roots $\mathrm{Zn}$ is accumulated as Zn-phytate (a

738 polyphosphate) or Zn-histidine (M onsant et al. 2011). In the leaves, a mixture of Zn-citrate and

$739 \mathrm{Zn}$-malate predominates in the epidermis while $\mathrm{Zn}$-NA is the main form in the mesophyll

740 (Schneider et al. 2013). According to ab initio calculations, Zn complexes with histidine are

741 isotopically lighter than with citrates, malates, and phosphates by roughly $-0.4,-0.3$, and $-1 \%$,

742 respectively (Fujii et al. 2014). Besides, Zn-phosphates are isotopically heavier than Zn-citrates

743 and Zn-malates by around $0.8 \%$ (Fujii and Albarède 2012). The isotopic signature of Zn-NA

744 complexes found in this hyperaccumulator is not yet known. With the information available,

745 the isotope partitioning observed between the shoot and the root in N. caerulescens could be

746 explained by the distribution of phosphates, citrates, and malates. A different interpretation

747 was proposed by Tang and co-workers for the accumulation of ${ }^{66} \mathrm{Zn}$ in the roots of $\mathrm{N}$.

748 caerulescens: the preferential transfer of ${ }^{64} \mathrm{Zn}$ to the xylem by means of the NcHMA4

749 transporter (Tang et al. 2012). This plasma membrane transporter orthologous to arabidopsis

750 AtHMA4 is highly expressed in the vascular tissue of $\mathrm{N}$. caerulescens due to multiple gene

751 copies (Ó Lochlainn et al. 2011), and is likely to be responsible for the increased export of Zn to

752 the xylem in this species that is part of the hyperaccumulation response (Papoyan and Kochian

753 2004; Craciun et al. 2012). Two other transporters, NcZNT1 and NcM TP1, are up-regulated in

754 N. caerulescens. The plasma membrane protein NcZNT1 is expressed in the root epidermis and

755 vasculature, and is involved both in $\mathrm{Zn}$ uptake in the root and $\mathrm{Zn}$ transport to the shoot. The

756 tonoplast transporter NCMTP1 ( $=$ NcZTP1, TcZTP1) is expressed mainly in leaves and

757 contributes to Zn sequestration in the vacuoles (Küpper and Kochian 2010; M ilner et al. 2012).

758 Similar transporters have been identified in other Zn hyperaccumulators, like AhM TP1 and

759 AhHM A3 in A. halleri, or NgM TP1 in Noccaea goesingensis ([Halácsy] F.K.M ey] (Becher et al.

760 2004; Shahzad et al. 2010). The increased activity of the above transporters could explain the

761 accumulation of ${ }^{64} \mathrm{Zn}$ in the shoots of hyperaccumulators. 
763 Isotopic fractionation of iron by plants

764 Iron uptake in strategy I and II plants

765 Iron can change its oxidation state during uptake or translocation within the plant, and those

766 redox conversions induce large isotopic fractionation. Strategy I plants (non-graminaceous

767 species) use the proton ATPase AHA2 localized to the plasma membrane to release protons to

768 the rhizosphere during Fe deficiency, increasing the solubility of Fe(III) (Santi and Schmidt

769 2009). The ferric reductase oxidase FRO2 then reduces the Fe(III) complexes at the plasma

770 membrane to aqueous Fe(II) (Robinson et al. 1999). Finally, Fe(II) is taken up by the roots via

771 the plasma membrane protein IRT1, the main high-affinity Fe transporter of the plant root

772 (Vert et al. 2002). By contrast, strategy II plants secrete PS to the rhizosphere to solubilise

773 Fe(III) during Fe deficiency (Takagi et al. 2008). The Fe(III)-PS complexes are transported into

774 the root symplast by plasma membrane transporters of the OPT family like ZmYS1 in maize,

775 HvYS1 in barley, and OsYSL15 in rice (Murata et al. 2006; Ueno et al. 2009; Inoue et al. 2009;

776 Suzuki et al. 2012). In a survey involving ten species grown in agricultural soil, the stems,

777 leaves, and grains of strategy I plants accumulated ${ }^{54} \mathrm{Fe}$ compared to the soil $\left(\Delta^{56} \mathrm{Fe}_{\mathrm{x} \text {-soil }}\right.$ up

778 to $-1.6 \%$, relative to the IRM M -014 standard), while those of strategy II plants (grasses) were

779 isotopically heavier ( $\Delta^{56} \mathrm{Fe}_{x-\text { soil }}$ up to $0.2 \%$ ) (Guelke and von Blanckenburg 2007). In aqueous

780 solutions, there is a strong fractionation of the isotopes between $\mathrm{Fe}(\mathrm{III})$ and $\mathrm{Fe}(\mathrm{II})$

$781\left(\Delta^{56} \mathrm{Fe}(\mathrm{III})-\mathrm{Fe}(\mathrm{II})=2.8 \%\right.$ ), with the light isotopes accumulating in the $\mathrm{Fe}(\mathrm{II})$ (Johnson et al.

782 2002). The enrichment of ${ }^{54} \mathrm{Fe}$ in the aerial parts of strategy I plants was attributed to the

783 reduction of Fe(III) in the soil by FRO2 previous to high-affinity uptake. The enrichment of ${ }^{56} \mathrm{Fe}$

784 in the aerial parts of strategy I plants was best explained by isotopically heavy Fe(III) binding to

785 PS in the soil.

786 However, Strategy II plants produce little PS in absence of Fe-deficiency (Cakmak et al. 1994;

787 Suzuki et al. 2006; Suzuki et al. 2008). The alpine species Oxyria digyna ([L.] Hill) and Rumex 
scutatus (L.), both strategy I, showed an enrichment of the light isotopes in the entire plants

789 relative to the soil ( $\Delta^{56} \mathrm{Fe}_{\text {plant-soil }}-0.60$ for 0 . digyna and $-1.03 \%$ for $\mathrm{R}$. scutatus), while in the

790 graminaceous Agrostis gigantea (Roth) there was very little fractionation (-0.07\%o)(Kiczka et al.

791 2010b). The partitioning of $\mathrm{Fe}$ isotopes in the two dicots was attributed to $\mathrm{H}^{+}$and

792 ligand-promoted Fe dissolution from the soil, which favours light isotopes (Wiederhold et al.

793 2006; Chapman et al. 2009; Kiczka et al. 2010a). The smaller fractionation in A. gigantea was

794 ascribed to different strategy II phenomena not involving PS, like Fe binding to other root

795 exudates. The authors argued that the amount of available Fe in the soil $\left(1500 \mu \mathrm{g} \mathrm{g}^{-1}\right)$ was very

796 high, and the Fe content of plant samples was not indicative of Fe deficiency, making PS

797 contribution to Fe uptake unlikely. In beans (Phaseolus vulgaris L., strategy I) and oats (Avena

798 sativa L., strategy II) grown in a nutritive solution containing $20 \mu \mathrm{M} \mathrm{Fe(III)-EDTA} \mathrm{(Fe-sufficient),}$

799 the light isotopes were enriched in both species, but the magnitude of $\Delta^{56} \mathrm{Fe}_{\text {plant-solution was }}$

800 larger in bean (-1.2\%) than in oats $(-0.5 \%$ ) (Guelke-Stelling and von Blanckenburg 2011). The

801 accumulation of light isotopes in both plants was explained by Fe(III)-EDTA reduction followed

802 by the uptake of $\mathrm{Fe}^{2+}$ on the surface of the roots. Reduction of $\mathrm{Fe}(\mathrm{III})$-chelates is a mechanism

803 present both in strategy I and II plants in absence of Fe-deficiency (Bienfait et al. 1983;

804 Bruggemann and M oog 1989). To account for the smaller magnitude of $\Delta^{56} \mathrm{Fe}_{\text {plant-solution in oats, }}$

805 Guelke-Stelling and von Blankenburg proposed that two mechanisms could compete with the

806 reduction of Fe(III)-complexes: i) direct uptake of Fe(III)-EDTA complexes, or ii) Fe(III) binding

807 to PS or phosphates in the apoplast. The uptake of either Fe(III)-EDTA or Fe(III)-PS would not

808 fractionate Fe isotopes, but the ligand exchange (from EDTA to PS) likely would. The Fe(III)-PS

809 complexes have a lower stability constant $\left(10^{18}\right)$ (Murakami et al. 1989) than the Fe(III)-EDTA

810 complexes $\left(10^{25}\right)$ (Smith and Martell 1989), which means that the lighter isotopes would

811 accumulate in the PS complexes, the species with the weaker bonds (Criss 1999). The direct

812 uptake of Fe(III)-chelates has been reported in strategy I and II species (Römheld and

813 Marschner 1981; Orera et al. 2010). Strategy II plants secrete PS in absence of Fe-deficiency, 
814 although the release rate is smaller (Erenoglu et al. 2000). However, PS release in oats greatly

815 depends on the cultivar, with Fe-inefficient varieties apparently not capable of producing

816 much PS even in Fe-deficient conditions (Jolley and Brown 1989). The amount of PS released to

817 the solution, the forms of Fe predominant in the shoots, and the oats cultivar used were not

818 indicated in the Guelke-Stelling and von Blankenburg study. This makes it difficult to establish

819 which of the two proposed uptake routes (reduction combined with direct uptake of

820 Fe-chelates, or uptake of Fe-PS complexes) predominates in Fe-sufficient oats.

821 Another mechanism for Fe uptake has been suggested for rice. The shoots of rice grown in

822 aerobic and anaerobic conditions had the same fractionation relative to the soil $\left(\Delta^{56} \mathrm{Fe}\right.$ shoot-soil

823 up to $-0.5 \%$ ) in spite of the likely difference in Fe redox forms and concentration of Fe(III)-PS

824 complexes (Arnold et al. 2015), and the magnitude of the fractionation was smaller than in

825 previous work (Guelke and von Blanckenburg 2007; Kiczka et al. 2010b). It was suggested that

826 a substantial amount of Fe was absorbed directly as $\mathrm{Fe}^{2+}$ and translocated up the shoot with no

827 redox conversions (Arnold et al. 2015), since rice can take $\mathrm{Fe}^{2+}$ up from the soil in aqueous

828 form directly and without previous solubilization by PS (Ishimaru et al. 2006). Future work

829 must be addressed to test this hypothesis by complementing the isotope data with additional 830 data, including Fe speciation in plants and soils, and PS release.

831

832 Xylem loading and unloading of Fe

833 Further discrimination of the isotopes occurs during Fe translocation within the plant. In

834 strategy I and II plants growing in Fe-sufficient soil, where a smaller contribution from PS could

835 be expected, the conductive tissue of the root (stele) was isotopically lighter than aerial parts

836 of the plant $\left(\Delta^{56} \mathrm{Fe}_{\text {stem-stele }}\right.$ up to $3.0 \%$ ) (Kiczka et al. 2010b). This was attributed to the

837 reduction of apoplastic Fe(III) and transfer of Fe(II) across the cell membrane, and to the

838 oxidation of Fe(II) to Fe(III) during the formation of Fe(III)-citrate complexes, which would then

839 be exported to the xylem leaving the symplast of the stele isotopically lighter. The main form 
840 of $\mathrm{Fe}$ in the symplast is Fe(II)-NA, while Fe in the xylem is Fe(III)-citrate (Rellán-Alvarez et al.

841 2008; Rellán-Alvarez et al. 2010). This is in agreement with ab initio calculations of isotopic

842 fractionation between Fe species, which predict that Fe(II)-NA would be isotopically lighter

$843(\approx 2 \%$ ) than Fe(III)-citrate (Moynier et al. 2013). Moynier and co-workers noted that while

844 redox changes accounted for the largest isotopic fractionations $(\approx 3 \%)$, speciation only could explain isotopic fractionations up to $1.5 \%$.

In beans (strategy I) grown in $20 \mu \mathrm{M}$ Fe(III)-EDTA solution $\delta^{56} \mathrm{Fe}$ decreased progressively from

847 the stem to the leaves and the grains $\left(\delta^{56} \mathrm{Fe}-0.31,-0.69\right.$, and $-1.90 \%$ o respectively) (GuelkeStelling and von Blanckenburg 2011). By contrast, no discrimination was observed between the aerial parts and the roots in oats (strategy II) in the same study. The authors attributed the fractionation pattern of beans to the reduction of $\mathrm{Fe}(\mathrm{III})$ in the xylem to $\mathrm{Fe}(\mathrm{II})$ during transfer to the symplast of leaves and grains. The absence of fractionation in the above-ground organs in oats is compatible with the translocation of Fe(III)-PS complexes from the root to the shoot, and with the transfer of Fe(III) from Fe(III)-PS or Fe(III)-EDTA to NA without changing the redox form. In strategy II plants Fe(III) can be transported up the shoot as Fe(III)-NA complexes without a previous reduction step (von Wiren et al. 1999).

Fe remobilization from older leaves to developing organs

In two Fe-deficient soils, the leaves of beans became depleted of ${ }^{56} \mathrm{Fe}$ between the first harvest and the fourth by up to $-0.7 \%$ (Guelke and von Blanckenburg 2007). The remobilization of Fe from older leaves to developing organs was proposed as the origin of this pattern. Excess Fe is oxidized to Fe(III) and stored as phytoferritin in the plastids of plant cells, from where it can be mobilised upon demand (van der Mark et al. 1982). It was argued that a non-quantitative sequestration of $\mathrm{Fe}$ in the phytoferritin complexes would favour the accumulation of

864 isotopically heavy Fe(III) in the phytoferritin, leaving a pool of isotopically light Fe(II) in the cytoplasm available for export to the developing tissues, and isotopically heavier older leaves. 
866 In the same study, the leaves of oats and wheat did not show substantial fractionation

867 between the first and the second harvest (Guelke and von Blanckenburg 2007). The authors

868 proposed that in strategy II plants Fe could move in the phloem as Fe(III) binding to heavy mass ligands such as NA. Iron (III) can form complexes with NA (von Wiren et al. 1999), but a study of the chemical forms of Fe in the phloem sap of rice has detected Fe(III)-PS complexes instead of Fe(III)-NA complexes (Nishiyama et al. 2012). In the Fe-deficient soils where oats and wheat were grown in the Guelke and von Blankenburg study a strong contribution of PS to Fe uptake can be expected, so Fe(III) could move in the phloem as Fe(III)-PS. In agreement, the grains of rice grown both in aerobic and anaerobic Fe-deficient soils had a similar composition as the shoot (Arnold et al. 2015).

Similar results were obtained in beans and oats grown in Fe-sufficient nutritive solution where

877 Fe was given as Fe(III)-EDTA. The youngest leaves and the seeds of beans became isotopically 878 lighter as plants grew (up to $-1.75 \%$ ), but those of oats did not (Guelke-Stelling and von 879 Blanckenburg 2011). By contrast, the leaves of both strategy I and II alpine species grown in an 880 Fe-rich soil (where very little contribution from PS to Fe uptake could be expected) 881 accumulated ${ }^{56} \mathrm{Fe}$ with age (up to 1.5\%o) (Kiczka et al. 2010b). Therefore it appears that in strategy II species the source of Fe determines the isotopic fractionation during remobilization. The uptake of Fe(III) binding to strong ligands like EDTA or PS causes no fractionation during Fe movement in the phloem, while the uptake of non-complexed Fe leads to a fractionation pattern analogous to that of strategy I species, indicative of a series of redox conversions. The partitioning of Fe isotopes between older and younger leaves is similar to that previously discussed in section 5.2 for $\mathrm{Zn}$. The light $\mathrm{Zn}$ isotopes become enriched in the leaves with height. This effect could be an evidence of $\mathrm{Zn}$ isotope partitioning during $\mathrm{Zn}$ remobilization

889 from older leaves to developing ones, analogous to that observed in Fe. While excess Fe is 890 stored in the plastids in form of phytoferritin, excess $\mathrm{Zn}$ is stored in the vacuoles of the leaves 891 in form of Zn complexes with citrate, malate, or NA (Aucour et al. 2011; Tang et al. 2012). 
892 M oreover, Zn can bind to more than 1,000 proteins in the cytoplasm of plant cells (Broadley et

893 al. 2007). If the heavy isotopes were enriched in the $\mathrm{Zn}$ bound to organic acids, amino acids,

894 and proteins, this would leave an isotopically lighter $\mathrm{Zn}^{2+}$ pool available for transport. The constant mobilization of micronutrients from older to younger leaves as new leaves appear could thus explain the gradation in the isotope composition of the leaves with age for both Fe and Zn.

898

899

\section{Copper}

900 Fewer studies have focused on the isotopic fractionation of $\mathrm{Cu}$ in plants. Lentils (Lens culinaris

901 Med.) germinated in distilled water showed a marked accumulation of ${ }^{63} \mathrm{Cu}$ in shoots relative 902 to seeds, i.e. $\Delta^{65} \mathrm{Cu}_{\text {shoot-seed }}$ of $-0.34 \%$ (Weinstein et al. 2011). This effect was identical to that 903 reported for $\mathrm{Zn}$ in the same experiment, i.e. $\Delta^{66} \mathrm{Zn}_{\text {shoot-seed }}=-0.34 \%$ (M oynier et al. 2009). In 904 the study conducted by Weinstein and co-workers, aerial parts of Elymus virginicus (L.) were 905 isotopically lighter than soil $(-0.94$ to $-0.33 \%$ ) , and leaves lighter than stems $(-0.39$ to $-0.13 \%)$. 906 Furthermore, the $\delta^{65} \mathrm{Cu}_{\text {NIst976 }}$ of the leaves of Carex hirsutella (Mackenzie) decreased with 907 height (from 7 to $43.5 \mathrm{~cm}$ ), and the linear relationship between them $\left(\delta^{65} \mathrm{Cu}=0.01 * \mathrm{H}-0.07\right.$, 908 where $\mathrm{H}$ is the height in $\mathrm{cm}$ ) was remarkably similar to that previously noted for $\mathrm{Zn}$ in bamboo $\left(\delta^{66} \mathrm{Zn}=-0.01 * \mathrm{H}-0.06\right)$ (Moynier et al. 2009; Weinstein et al. 2011). The authors concluded that both $\mathrm{Cu}$ and $\mathrm{Zn}$ were submitted to the same fractionation mechanisms during uptake and

911 translocation, probably during transport across the cell membranes. However, a distinct 912 pattern of fractionation during $\mathrm{Cu}$ uptake was later described in rice, lettuce, tomato, and 913 durum wheat grown hydroponically (Jouvin et al. 2012). In these species, shoots accumulated $914{ }^{63} \mathrm{Cu}$ relative to the solution in a range very similar to that of the Weinstein study $915\left(\Delta^{65} \mathrm{Cu}_{\text {shoot-solution }}-1.06\right.$ to $-0.34 \%$ ), and the roots generally had the same isotopic composition 916 as the shoots $\left(\Delta^{65} \mathrm{Cu}\right.$ root-solution -0.84 to $-0.11 \%$ ). The accumulation of ${ }^{63} \mathrm{Cu}$ in the roots was 917 similar to that previously reported for ${ }^{54} \mathrm{Fe}$ in beans and oats $\left(\Delta^{56} \mathrm{Fe}_{\text {root-solution }}=-1.0\right.$ to $\left.-0.5 \%\right)$, 
918 which was attributed to Fe(III) reduction during Fe uptake (Guelke-Stelling and von

919 Blanckenburg 2011). By contrast, $\mathrm{Zn}$ in the roots is typically enriched in heavy isotopes $920\left(\Delta^{66} \mathrm{Zn}\right.$ root-solution up to 0.8\%)(Weiss et al. 2005; Viers et al. 2007; Aucour et al. 2011). It was 921 concluded that the enrichment of ${ }^{63} \mathrm{Cu}$ in the roots was due to the reduction of $\mathrm{Cu}(\mathrm{II})$ to $\mathrm{Cu}(\mathrm{I})$ during $\mathrm{Cu}$ uptake by the root cells. Leaching of $\mathrm{Cu}(\mathrm{I})$ minerals has shown that ${ }^{65} \mathrm{Cu}$ accumulates in the aqueous $\mathrm{Cu}(\mathrm{II})\left({ }^{65} \mathrm{C} \mathrm{u}_{\text {mineral-solution }}-1.18\right.$ to $-0.94 \%$ )(Kimball et al. 2009). The fractionation during $\mathrm{Cu}(\mathrm{II})$ reduction to $\mathrm{Cu}(\mathrm{I})$ is similar to the fractionation observed during $\mathrm{Cu}$ uptake by the root by Jouvin and co-workers $\left({ }^{65} \mathrm{Cu}_{\text {root-solution }}-0.84\right.$ to $-0.11 \%$ ). The smaller fractionation in plants indicates a combination of reduction and another uptake mechanism that does not fractionate isotopes or takes a shift towards the heavy. In arabidopsis, $\mathrm{Cu}(\mathrm{II})$ reduction to $\mathrm{Cu}(\mathrm{I})$ is a pre-requisite for the high-affinity uptake of $\mathrm{Cu}$ by means of the transporter COPT1, and is mediated by the ferric reductase oxidases FRO5 and FRO4 (Bernal et al. 2012). The reductase

930 FRO2 is responsible for Fe(III) reduction to $\mathrm{Fe}(\mathrm{II})$ prior to uptake mediated by the IRT1 931 transporter, as discussed in the previous section. The reductase activity of the FRO family thus 932 constitutes an important link between $\mathrm{Cu}$ and Fe homeostasis. Still, transporter COPT1 is 933 responsible for only $40-60 \%$ of $\mathrm{Cu}$ uptake in arabidopsis under adequate $\mathrm{Cu}$ nutrition 934 (Sancenón et al. 2004). Plants take up $\mathrm{Cu}(\mathrm{II})$ in form of $\mathrm{Cu}^{2+}$ or PS-Cu(II) complexes (Roberts et al. 2004; Hötzer et al. 2012). The transport of $\mathrm{Cu}^{2+}$ across the cell membrane during uptake in the roots is probably facilitated by cation transporters like ZIP2 in arabidopsis, and IRT1 and

937 IRT2 in tomato (Wintz et al. 2003; George et al. 2012). The uptake of PS complexes with Cu(II) 938 is mediated by plasma membrane transporters in the root epidermis like YS1 in maize (Roberts 939 et al. 2004). In agreement, the roots of tomato and oats grown in Fe-sufficient nutrient 940 solution were enriched in light isotopes relative to the solution, and the shift was much larger 941 in tomato $\left(\triangle^{65} \mathrm{Cu}_{\text {root-solution }}-1.43 \%\right.$ ) than in oats ( $-0.20 \%$ )(Ryan et al. 2013$)$. In both species the

942 fractionation decreased during Fe-deficiency $(-1.05 \%$ and $-0.12 \%$ respectively) indicating a 943 greater uptake of $\mathrm{Cu}(\mathrm{II})$, probably as $\mathrm{Cu}(\mathrm{II})$ complexes with root exudates. The smaller 
944 fractionation in oats, a strategy II plant, points to a substantial uptake of PS-Cu(II) complexes in 945 this species.

946 Further isotope effects have been reported during Cu transport to stem and leaves. In tomato,

947 the translocation of $\mathrm{Cu}$ up the shoots favoured ${ }^{65} \mathrm{Cu}\left(\Delta^{65} \mathrm{Cu}_{\text {shoot-root }}\right.$ up to $1.0 \%$ ), suggesting that

$948 \mathrm{Cu}(\mathrm{I})$ was oxidised to $\mathrm{Cu}(\mathrm{II})$ before its export to the xylem (Ryan et al. 2013). In agreement, $\mathrm{Cu}$

949 is mostly present as Cu(II)-NA complexes in the xylem (Curie et al. 2009). By contrast, the

950 transfer of $\mathrm{Cu}$ from the stem to the leaves favoured the light isotopes $\left(\Delta^{65} \mathrm{Cu}_{\text {leaves-stem }}\right.$ up

951 to $-0.37 \%$ ), which points to reduction of $\mathrm{Cu}(\mathrm{II})$ to $\mathrm{Cu}(\mathrm{I})$ during $\mathrm{Cu}$ unloading from the xylem

952 (Ryan et al. 2013). Transporter COPT6 in arabidopsis is expressed in the vasculature of the

953 shoot and might be involved in $\mathrm{Cu}(\mathrm{I})$ import into the leaf symplast (Jung et al. 2012). This

954 transporter has a high specificity for $\mathrm{Cu}(\mathrm{I})$ and requires the previous reduction of $\mathrm{Cu}(\mathrm{II})$ to $\mathrm{Cu}(\mathrm{I})$.

955 This reduction is probably catalysed by the reductase FRO3, which is expressed in the

956 vasculature of the shoot in response to both Fe and Cu deficiency (M ukherjee et al. 2006). In

957 oats, roots, stems, and leaves had the same isotopic composition (Ryan et al. 2013). This

958 suggests that strategy II plants might have different translocation mechanisms for $\mathrm{Cu}$ not

959 involving redox conversions, as discussed for $\mathrm{Fe}$ in the previous section. The $\mathrm{Cu}(\mathrm{II})$ in PS 960 complexes might be transferred to NA in the xylem with no further redox conversion. In 961 strategy II plants, Fe could be transported up the shoot as Fe(III)-NA complexes without a 962 previous reduction step (von Wiren et al. 1999). In rice, the transporter YSL16 can transport $963 \mathrm{Cu}(\mathrm{II})-\mathrm{NA}$ complexes from the xylem directly into the phloem to nourish the developing leaves

964 (Zheng et al. 2012). Finally, the green leaves of tomato were enriched in light isotopes relative 965 to the chlorotic ones by $-0.30 \%$, suggesting that the remobilization of $\mathrm{Cu}$ to the developing 966 organs favours the light isotopes, as previously discussed for Fe and Zn (Ryan et al. 2013). 967 However, in oats the green leaves were enriched in heavy isotopes as compared with the 968 chlorotic ones by $0.27 \%$, which points to $\mathrm{Cu}$ reduction during remobilization of nutrients in 969 oats. 


\section{$971 \quad$ Nickel}

972 Very little is known about Ni isotopic fractionation in plants, but it is still worth discussing it

973 here because many metalicollous plants are $\mathrm{Zn}$ and $\mathrm{Ni}$ hyperaccumulators (Prasad and De

974 Oliveira Freitas 2003). A survey of $\mathrm{Ni}$ isotopic fractionation in plants including a

975 non-hyperaccumulator (Thlaspi arvense L.), a Ni hyperaccumulator (Alyssum murale Waldst. \&

976 Kit.), and a $\mathrm{Ni}$ and $\mathrm{Zn}$ hyperaccumulator ( $\mathrm{N}$. caerulescens) revealed that plants generally

977 accumulate light isotopes during uptake $\left(\Delta^{60} \mathrm{Ni}_{\text {plant-solution }}-0.90\right.$ to $-0.21 \%$, relative to NIST-SRM

978 986)(Deng et al. 2014). The hyperaccumulators showed a larger fractionation (-0.90 979 to $-0.63 \%$ ), which points to a greater permeability of the low-affinity transporters in these 980 species (Deng et al. 2014). Interestingly, a high supply of $\mathrm{Zn}\left(50 \times 10^{-6} \mathrm{M}\right)$ suppressed the 981 observed fractionation in all the three species $(-0.11$ to $-0.07 \%$ ). This indicates that $\mathrm{Zn}$ and $\mathrm{Ni}$ 982 compete for the same uptake mechanisms. The root to shoot transfer of $\mathrm{Ni}$ resulted in further 983 enrichment of ${ }^{58} \mathrm{Ni}$ in the hyperaccumulators $(-0.47$ to $-0.14 \%$ ), while the shoots of the 984 non-hyperaccumulator accumulated ${ }^{60} \mathrm{Ni}$ relative to the roots $(0.25 \%)$. This suggests the 985 existence of different $\mathrm{Ni}$ translocation mechanisms in hyperaccumulators, but these remain 986 poorly understood.

987

\section{Model of $\mathbf{Z n}$ isotope discrimination by plants}

989 The isotope data recently published permit to confirm and improve upon the model developed

990 by Jouvin and co-workers (Jouvin et al. 2012) (Fig. 5), which identified the most likely sources 991 of isotope discrimination during Zn uptake by plants roots. Zinc in the soil solution will bind 992 with suitable ligands, such as the low-molecular weight compounds in the root exudates (PS, 993 OA, etc.) and the cellulose and pectin of the cell walls. Alternatively, Zn might bind covalently 994 to phosphates in the apoplast as proposed by Fujii and Albarède 2012, or to silicates (M edas et 995 al. 2015). In the light of the experimental evidence discussed above, these reactions seem to 
996 favour the accumulation of heavy isotopes in the resulting $\mathrm{Zn}$-complexes relative to free $\mathrm{Zn}^{2+}$.

997 Unbound $\mathrm{Zn}^{2+}$ can move by diffusion over small distances in the un-stirred layer around the

998 roots, a kinetically controlled reaction that would favour the lighter isotopes (Criss 1999). The

999 fractionation of $\mathrm{Zn}$ isotopes caused by the joint activity of the plasma membrane transporters

1000 would depend on the concentration and predominant $\mathrm{Zn}$ species in the rhizosphere. Jouvin

1001 and co-workers proposed in their model that low-affinity uptake of $\mathrm{Zn}^{2+}$ mediated by ion

1002 channels would work towards the accumulation of light isotopes in the cytosol of the root cells

1003 relative to the apoplast, due to the faster diffusion of the light isotopes, whereas high-affinity

1004 uptake would favour the heavy isotopes due to the covalent binding of $\mathrm{Zn}$ with these

1005 transporters (Jouvin et al. 2012). This latter notion has been recently challenged by Tang and

1006 co-workers, who proposed that high-affinity uptake would not fractionate $\mathrm{Zn}$ isotopes (Tang et

1007 al. 2016). They observed a small enrichment of the light isotopes in plants relative to the

1008 solution which was larger in the non-accumulator T. arvense ( -0.16 to $-0.26 \%$ ) than in the

1009 hyperaccumulator $N$. caerulescens $(-0.06$ to $-0.12 \%)$. They attributed their results to i)

1010 diffusional fractionation caused by a depletion zone around the roots in hyperaccumulators

1011 and ii) a mixture of high- and low-affinity transport in non-accumulators. Experiments in

1012 diatoms have shown that the light isotopes are enriched in the cell relative to the growth

1013 solution during high-affinity uptake (John et al. 2007). Besides, it is not yet clear if the ZIP

1014 transporters mainly responsible for $\mathrm{Zn}^{2+}$ uptake at the root function as ion channels or as

1015 carrier proteins, how $\mathrm{Zn}$ binds to these proteins, or how $\mathrm{Zn}$ is transported across the membrane. In our view, both low- and high-affinity $\mathrm{Zn}^{2+}$ transporters discriminate in favour of

1017 the light isotopes, but the magnitude of this effect would be smaller during high-affinity 1018 uptake because the higher efficiency of these transporters would make them less selective of 1019 the isotopes (as proposed by John et al. 2007). Finally, the uptake of Zn-complexes would not 1020 further discriminate $\mathrm{Zn}$ isotopes because of the large mass of the complexes. However, non1021 quantitative uptake of Zn-complex would result in the enrichment of heavy isotopes in plants 
1022 relative to the soil solution, because the $\mathrm{Zn}$-complexes themselves are isotopically heavier

1023 than the unbound $\mathrm{Zn}^{2+}$. Efflux transporters would probably carry isotopically light $\mathrm{Zn}^{2+}$ to the 1024 rhizosphere, but their contribution is likely to be small. In Zn-sufficient environments, the main 1025 sources of isotope separation at the soil-root interface identified were $\mathrm{Zn}$ speciation in the soil 1026 solution, binding to the cell walls, and low-affinity transport phenomena. In Zn-deficient 1027 conditions, these were substituted by high-affinity transport phenomena, $\mathrm{Zn}$ binding to root exudates, and the uptake of the resulting complexes. The two latter are especially relevant in Strategy II plants. Finally, Zn isotopic fractionation at the soil-root interface with high Zn supply originated mostly from Zn binding to the cell wall.

1031 Jouvin and co-workers addressed only briefly some of the mechanisms that could lead to isotopic fractionation during $\mathrm{Zn}$ transfer from the root to the shoot: i) complexation with various ligands in the xylem and phloem, especially NA, ii) membrane crossings, iii) diffusion, 1034 and iv) ion exchange (Jouvin et al. 2012). Here we would like to build on their preliminary 1035 model and provide a detailed account of all the likely sources of fractionation at work during 1036 Zn export to the shoots and movement between above-ground organs. Following Zn uptake by 1037 the root, $\mathrm{Zn}^{2+}$ in the cytosol binds to small weight compounds, most likely NA (Fig. 6). Heavy 1038 isotopes are thought to accumulate in the resulting $\mathrm{Zn}$-complexes relative to the $\mathrm{Zn}^{2+}$ fraction. 1039 Unbound $\mathrm{Zn}^{2+}$ can diffuse radially over small distances in the apoplast and the symplast, passing from the cytoplasm of one cell to another across the plasmodesmata. Lighter isotopes will diffuse faster due to their smaller mass. In our model, we propose that the vacuoles might have a key role in determining the isotopic composition of the $\mathrm{Zn}$ pool of the cytosol. Excess

$1043 \mathrm{Zn}^{2+}$ can be removed from the cytosol and stored in the vacuole by means of vacuolar 1044 transporters, wherefrom it can be remobilized. In this manner, vacuolar transporters control 1045 the amount of $\mathrm{Zn}$ available for export to the aerial parts. The isotopic composition of the 1046 vacuolar Zn pool is unknown and probably very dynamic, determined by the joint activity of 1047 the vacuolar transporters and Zn speciation in the vacuole. 
1048 Zinc will be loaded onto the xylem sap from the cytosol of the adjacent cells, a step mediated

1049 by membrane transporters that seem to favour the lighter isotopes. Zinc in the xylem sap 1050 mostly consists of $\mathrm{Zn}^{2+}$, but a substantial amount of $\mathrm{Zn}$-complexes with $\mathrm{OA}$, histidine, NA, and 1051 PS might be present, especially under low Zn supply (Fig. 7). The xylem sap moves up the stem 1052 thanks to the mass flow of water driven by transpiration and maintained by the cohesion of 1053 the water molecules and their adhesion to the cellulose walls. This movement might result in 1054 the enrichment of light isotopes in the leaves with height, although it is not yet clear how the isotopes could be discriminated. Adsorption of $\mathrm{Zn}^{2+}$ onto the cellulose walls of the xylem should result in a progressive depletion of the heavier isotopes in the xylem sap relative to the root symplast. From the xylem, $\mathrm{Zn}$ will enter the leaf symplast via $\mathrm{Zn}$ transporters at the plasma membrane of the bundle sheath cells, specialized in xylem unloading. Xylem unloading

1059 might favour the accumulation of lighter isotopes in the leaves relative to the xylem sap.

1060 In the leaf symplast $\mathrm{Zn}^{2+}$ will bind to various ligands, mainly NA, accumulating heavy isotopes in 1061 the complexes relative to free $\mathrm{Zn}^{2+}$. Ligand exchange might also occur during $\mathrm{Zn}$ unloading 1062 from the xylem to the symplast, but the isotopic effects derived from it are not known. In 1063 addition, preferential diffusion of isotopically light $\mathrm{Zn}^{2+}$ in the symplast could lead to further 1064 discrimination of $\mathrm{Zn}$ isotopes during $\mathrm{Zn}$ movement in the leaves. The activity of the vacuolar 1065 transporters and $\mathrm{Zn}$ complexation in the cytosol and the vacuole regulate $\left[\mathrm{Zn}^{2+}\right]$ in the leaf symplast. These processes might leave an isotopically lighter pool of $\mathrm{Zn}^{2+}$ available for remobilization to developing leaves and grains. Znc remobilization from source to sink tissues involves phloem loading, xylem-to-phloem direct transfer, and phloem unloading of $\mathrm{Zn}$. All three processes are thought to be mediated by transporters at the plasma membrane, and 1070 likely favour the lighter isotopes.

1071

\section{Conclusions}


1073 The purpose of this review is to provide an overview of $\mathrm{Zn}$ isotopic fractionation in plants, in

1074 relation with our current knowledge of $\mathrm{Zn}$ homeostasis. The research debated here clearly

1075 indicates that $\mathrm{Zn}$ uptake, transport to the aerial parts, and transfer to the leaves can induce

1076 isotopic fractionation relative to the $\mathrm{Zn}$ source, and between the plant organs. The isotopic

1077 effects observed are species-specific and concentration-dependent, and are attributed mainly

1078 to Zn speciation, compartmentalization, and transporters. In future, isotope ratios may serve

1079 to elucidate the predominant $\mathrm{Zn}$ species taken up by the roots, and found in the various $\mathrm{Zn}$

1080 pools in the plant. Furthermore, isotope ratios could be used to identify the major processes

1081 controlling $\mathrm{Zn}$ transfer to the aerial parts and to quantify the extent of remobilization from

1082 source to sink organs, for instance during grain filling. Moreover, analysing the isotope ratios

1083 of Zn and other metals with similar biochemistry could reveal their competitive interactions.

1084 Additionally, changes in the patterns of $\mathrm{Zn}$ isotopic partitioning in response to environmental

1085 conditions might be used to study plant physiology and to identify desired traits like $\mathrm{Zn}$

1086 efficiency or hypertolerance.

1087 Future efforts must be directed towards the identification of the individual mechanisms

1088 responsible for the observed isotopic effects. To achieve this objective, research needs to solve 1089 several knowledge gaps. Probably the most urgent task is to constrain the isotopic effect 1090 associated with Zn binding to key ligands, like phytosiderophores, cellulose, pectine, OA, NA, 1091 and phosphates. Besides, the $\delta^{66} \mathrm{Zn}$ of subcellular compartments, plant tissues, and some 1092 organs (fruits, seeds, and rhizomes) has not been properly investigated yet, which is hampering our understanding of $\mathrm{Zn}$ flows in plants. Finally, the influence of many factors

1094 important for plant nutrition like soil biochemistry, Zn interactions with other nutrients, 1095 mycorrhizae, root iron plaque, and environmental stressors on the patterns of $\mathrm{Zn}$ isotope 1096 discrimination is still unexplored. 
1099 We are grateful to Martin Broadley and two anonymous reviewers for their critical comments

1100 that greatly improved the manuscript. We thank the European Union for financial contribution

1101 from the People Programme (M arie Curie Actions) Seventh Framework Programme FP7/2007-

$1102 \quad 2013 /$ under REA grant agreement $n^{\circ}$ [299473].

1103

1104

References

1105

Al-Fahdawi MS, Able JA, Evans M, Able AJ (2014) Response of durum wheat to different levels of zinc and Fusarium pseudograminearum. Crop Pasture Sci 65:61-73. doi:

1107 $10.1071 /$ CP13306

1108

Albarède F, Beard B (2004) Analytical M ethods for Non-Traditional Isotopes. Rev Mineral GEOCHEM ISTRY 55:113-152. doi: 10.2138/gsrmg.55.1.113

1110

Alloway BJ (2009) Soil factors associated with zinc deficiency in crops and humans. Environ Geochem Health 31:537-48. doi: 10.1007/s10653-009-9255-4

Arnold T, Kirk GJD, Wissuwa M, et al (2010) Evidence for the mechanisms of zinc uptake by rice using isotope fractionation. Plant Cell Environ 33:370-381. doi: 10.1111/j.13653040.2009.02085.x

Arnold T, Markovic T, Kirk GJD, et al (2015) Iron and zinc isotope fractionation during uptake and translocation in rice (Oryza sativa) grown in oxic and anoxic soils. Comptes Rendus Geosci 347:397-404. doi: 10.1016/j.crte.2015.05.005

Arrivault S, Senger T, Krämer U (2006) The Arabidopsis metal tolerance protein AtM TP3 maintains metal homeostasis by mediating $\mathrm{Zn}$ exclusion from the shoot under Fe deficiency and Zn oversupply. Plant J 46:861-879. doi: 10.1111/j.1365$313 X .2006 .02746 . x$

Aucour AM , Bedell JP, Queyron M, et al (2015) Dynamics of Zn in an urban wetland soil-plant system: Coupling isotopic and EXAFS approaches. Geochim Cosmochim Acta 160:55-69. doi: 10.1016/j.gca.2015.03.040 
1125 Aucour AM, Pichat S, M acNair M R, Oger P (2011) Fractionation of stable zinc isotopes in the 1126 zinc hyperaccumulator Arabidopsis halleri and nonaccumulator Arabidopsis petraea.

1127 Environ Sci Technol 45:9212-9217. doi: 10.1021/es200874x

1128 Becher M, Talke IN, Krall L, Krämer U (2004) Cross-species microarray transcript profiling 1129 reveals high constitutive expression of metal homeostasis genes in shoots of the zinc 1130 hyperaccumulator Arabidopsis halleri. Plant J 37:251-268. doi: 10.1046/j.1365-

1131 $313 \times .2003 .01959 . x$

1132

Becker M , Asch F (2005) Iron toxicity in rice-conditions and management concepts. J Plant Nutr Soil Sci 168:558-573. doi: 10.1002/jpln.200520504

Bernal M, Casero D, Singh V, et al (2012) Transcriptome sequencing identifies SPL7-regulated copper acquisition genes FRO4/FRO5 and the copper dependence of iron homeostasis in Arabidopsis. Plant Cell 24:738-61. doi: 10.1105/tpc.111.090431

1137

Bienfait HF, Bino RJ, Bliek AM, et al (1983) Characterization of ferric reducing activity in roots of Fe-deficient Phaseolus vulgaris. Physiol Plant 59:196-202. doi: 10.1111/j.13993054.1983.tb00757.x

Black JR, Epstein E, Rains WD, et al (2008) M agnesium-isotope fractionation during plant growth. Environ Sci Technol 42:7831-7836. doi: 10.1021/es8012722

Broadley M , Brown P, Cakmak I, et al (2012) M arschner's M ineral Nutrition of Higher Plants. Elsevier

Broadley M R, White PJ, Hammond JP, et al (2007) Zinc in plants. New Phytol 173:677-702. doi: $10.1111 /$ j.1469-8137.2007.01996.x

Bruggemann W, Moog PR (1989) NADH-dependent Fe3+EDTA and oxygen reduction by plasma membrane vesicles from barley roots. Physiol Plant 75:245-254. doi: 10.1111/j.13993054.1989.tb06176.x

Cakmak I, Erenoglu B, Gülüt KY, et al (1998a) Light-mediated release of phytosiderophores in wheat and barley under iron or zinc deficiency. Plant Soil 202:309-315. doi: 
1152 Cakmak I, Sari N, Marschner H, et al (1996) Phytosiderophore release in bread and durum 1153 wheat genotypes differing in zinc efficiency. Plant Soil 180:183-189. doi:

1154 10.1007/BF00015301

1155

Cakmak I, Torun B, Erenoglu B, et al (1998b) M orphological and physiological differences in the response of cereals to zinc deficiency. Euphytica 100:349-357. doi:

1157 10.1023/A:1018318005103

1158

Cakmak S, Gulut KY, M arschner H, Graham RD (1994) Effect of zinc and iron deficiency on phytosiderophore release in wheat genotypes differing in zinc efficiency. J plant Nutr 117. doi: $10.1080 / 01904169409364706$

Caldelas C, Dong S, Araus J L, Weiss DJ (2011) Zinc isotopic fractionation in Phragmites australis in response to toxic levels of zinc. J Exp Bot 62:2169-2178. doi: 10.1093/jxb/erq414

1163 Caulfield LE, Richard SA, Rivera JA, et al (2006) Stunting, Wasting, and Micronutrient Deficiency 1164 Disorders. In: Jamison DT, Breman JG, Measham AR et al. (ed) Disease Control Priorities in Developing Countries, 2nd editio. The World Bank, Oxford University Press, New York,

1167 Chapman JB, Weiss DJ, Shan Y, Lemburger M (2009) Iron isotope fractionation during leaching of granite and basalt by hydrochloric and oxalic acids. Geochim Cosmochim Acta 73:1312-1324. doi: 10.1016/j.gca.2008.11.037

Chu H-H, Chiecko J, Punshon T, et al (2010) Successful reproduction requires the function of Arabidopsis Yellow Stripe-Like1 and Yellow Stripe-Like3 metal-nicotianamine transporters

1174 Clemens S, Deinlein U, Ahmadi H, et al (2013) Nicotianamine is a major player in plant Zn 1175 homeostasis. Biometals 26:623-32. doi: 10.1007/s10534-013-9643-1

1176 Coleman JE (1992) Zinc proteins: enzymes, storage proteins, transcription factors, and 
replication proteins. Annu Rev Biochem 61:897-946. doi:

10.1146/annurev.bi.61.070192.004341

1179 Collins RN, Merrington G, M cLaughlin MJ, Knudsen C (2002) Uptake of intact zinc-

1180 ethylenediaminetetraacetic acid from soil is dependent on plant species and complex

1181 concentration. Environ Toxicol Chem 21:1940-5. doi: 10.1002/etc.5620210923

Cornu J-Y, Deinlein U, Höreth S, et al (2015) Contrasting effects of nicotianamine synthase knockdown on zinc and nickel tolerance and accumulation in the zinc/cadmium hyperaccumulator Arabidopsis halleri. New Phytol 206:738-50. doi: 10.1111/nph.13237

Couder E, M attielli N, Drouet T, et al (2015) Transpiration flow controls Zn transport in Brassica napus and Lolium multiflorum under toxic levels as evidenced from isotopic fractionation. Comptes Rendus Geosci. doi: 10.1016/j.crte.2015.05.004

Craciun AR, M eyer C-L, Chen J, et al (2012) Variation in HM A4 gene copy number and expression among Noccaea caerulescens populations presenting different levels of $\mathrm{Cd}$ tolerance and accumulation. J Exp Bot 63:4179-89. doi: 10.1093/jxb/ers104

1192 Curie C, Cassin G, Couch D, et al (2009) M etal movement within the plant: contribution of nicotianamine and yellow stripe 1-like transporters. Ann Bot 103:1-11. doi: $10.1093 / \mathrm{aob} / \mathrm{mcn} 207$

Daneshbakhsh B, Khoshgoftarmanesh AH, Shariatmadari H, Cakmak I (2013) Phytosiderophore release by wheat genotypes differing in zinc deficiency tolerance grown with $\mathrm{Zn}$-free

De Giudici G, Medas D, M eneghini C, et al (2015) Microscopic biomineralization processes and Zn bioavailability: a synchrotron-based investigation of Pistacia lentiscus L. roots. Environ Sci Pollut Res 22:19352-19361. doi: 10.1007/s11356-015-4808-9

1202 Degryse F, Verma VK, Smolders E (2007) M obilization of Cu and Zn by root exudates of 
dicotyledonous plants in resin-buffered solutions and in soil. Plant Soil 306:69-84. doi:

$1204 \quad 10.1007 /$ s11104-007-9449-4

1205 Deng T-H-B, Cloquet C, Tang Y-T, et al (2014) Nickel and zinc isotope fractionation in hyperaccumulating and nonaccumulating plants. Environ Sci Technol 48:11926-33. doi: $10.1021 /$ es5020955

Deniro MJ, Epstein S (1979) Relationship between the oxygen isotope ratios of terrestrial plant cellulose, carbon dioxide, and water. Science 204:51-3. doi: 10.1126/science.204.4388.51

Dinant S, Bonnemain J-L, Girousse C, Kehr J (2010) Phloem sap intricacy and interplay with aphid feeding. CR Biol 333:504-515. doi: 10.1016/j.crvi.2010.03.008

Duffner A, Hoffland E, Temminghoff EJM (2012) Bioavailability of zinc and phosphorus in calcareous soils as affected by citrate exudation. Plant Soil 361:165-175. doi: $10.1007 /$ s11104-012-1273-9

Eren E, Argüello JM (2004) Arabidopsis HM A2, a divalent heavy metal-transporting P(IB)-type ATPase, is involved in cytoplasmic Zn2+homeostasis. Plant Physiol 136:3712-23. doi: $10.1104 /$ pp.104.046292

Erenoglu B, Cakmak I, Marschner H, et al (1996) Phytosiderophore release does not relate well with zinc efficiency in different bread wheat genotypes.

Erenoglu B, Eker S, Cakmak I, et al (2000) Effect of iron and zinc deficiency on release of phytosiderophores in barley cultivars differing in zinc efficiency. J Plant Nutr 23:16451656. doi: $10.1080 / 01904160009382130$

Escarré J, Lefèbvre C, Raboyeau S, et al (2010) Heavy M etal Concentration Survey in Soils and Plants of the Les M alines M ining District (Southern France): Implications for Soil Restoration. Water, Air, Soil Pollut 216:485-504. doi: 10.1007/s11270-010-0547-1

1226 Farquhar G, O'Leary M , Berry J (1982) On the Relationship Between Carbon Isotope 1227 Discrimination and the Intercellular Carbon Dioxide Concentration in Leaves. Aust J Plant $1228 \quad$ Physiol 9:121. doi: 10.1071/PP9820121 
1229 Fu C, Li M, Zhang Y, et al (2015) M orphology, photosynthesis, and internal structure alterations

1230 in field apple leaves under hidden and acute zinc deficiency. Sci Hortic (Amsterdam)

1231 193:47-54. doi: 10.1016/j.scienta.2015.06.016

1232 Fujii T, Albarède F (2012) Ab initio calculation of the $Z n$ isotope effect in phosphates, citrates, and malates and applications to plants and soil. PLoS One 7:e30726. doi: 10.1371/journal.pone.0030726

Fujii T, M oynier F, Blichert-Toft J, Albarède F (2014) Density functional theory estimation of isotope fractionation of $\mathrm{Fe}, \mathrm{Ni}, \mathrm{Cu}$, and $\mathrm{Zn}$ among species relevant to geochemical and biological environments. Geochim Cosmochim Acta 140:553-576. doi: 10.1016/j.gca.2014.05.051

Gélabert A, Pokrovsky OS, Viers J, et al (2006) Interaction between zinc and freshwater and marine diatom species: Surface complexation and $\mathrm{Zn}$ isotope fractionation. Geochim

1242 George E, Horst WJ, Neumann E (2012) Adaptation of plants to adverse chemical soil conditions. In: M arschner P (ed) M arschner's M ineral Nutrition of Higher Plants, 3rd editio. Elsevier Ltd, Amsterdam, Boston, Heidelberg, London, New York, Oxford, Paris, San Diego, San Francisco, Singapore, Sydney, Tokyo, pp 409-472

Guelke-Stelling M , von Blanckenburg F (2011) Fe isotope fractionation caused by translocation of iron during growth of bean and oat as models of strategy I and II plants. Plant Soil 352:217-231. doi: 10.1007/s11104-011-0990-9 
1255 Guelke M, von Blanckenburg F (2007) Fractionation of Stable Iron Isotopes in Higher Plants.

$1256 \quad$ Environ Sci Technol 41:1896-1901. doi: 10.1021/es062288j

1257 Hacisalihoglu G, Hart J, Kochian L V (2001) High- and low-affinity zinc transport systems and

1258 their possible role in zinc efficiency in bread wheat. Plant Physiol 125:456-63. doi: 10.

1259 $1104 /$ pp.125.1.456

1260

Haydon MJ, Kawachi M, Wirtz M, et al (2012) Vacuolar nicotianamine has critical and distinct

1261 roles under iron deficiency and for zinc sequestration in Arabidopsis. Plant Cell 24:72437. doi: 10.1105/tpc. 111.095042

Hazama K, Nagata S, Fujimori T, et al (2015) Concentrations of metals and potential metal-

1264

1265

1266 binding compounds and speciation of $\mathrm{Cd}, \mathrm{Zn}$ and $\mathrm{Cu}$ in phloem and xylem saps from

Hötzer B, Ivanov R, Brumbarova T, et al (2012) Visualization of $\mathrm{Cu}^{2+}$ uptake and release in plant cells by fluorescence lifetime imaging microscopy. FEBS J 279:410-9. doi: 10.1111/j.17424658.2011.08434.x

Houben D, Sonnet P (2012) Zinc mineral weathering as affected by plant roots. Appl Geochemistry 27:1587-1592. doi: 10.1016/j.apgeochem.2012.05.004

Houben D, Sonnet P, Tricot G, et al (2014) Impact of root-induced mobilization of zinc on stable Zn isotope variation in the soil-plant system. Environ Sci Technol 48:7866-7873. doi:

$$
10.1021 / \text { es5002874 }
$$

Imran M, Rehim A, Sarwar N, Hussain S (2016) Zinc bioavailability in maize grains in response of phosphorous-zinc interaction. J Plant Nutr Soil Sci 179:60-66. doi: 10.1002/jpln.201500441 deoxymugineic acid transporter expressed in the roots and is essential for iron uptake in early growth of the seedlings. J Biol Chem 284:3470-9. doi: 10.1074/jbc.M 806042200 
1281 Ishimaru Y, Suzuki M, Kobayashi T, et al (2005) OsZIP4, a novel zinc-regulated zinc transporter

1282 in rice. J Exp Bot 56:3207-14. doi: 10.1093/jxb/eri317

1283 Ishimaru Y, Suzuki M, Tsukamoto T, et al (2006) Rice plants take up iron as an Fe 3+-

1284 phytosiderophore and as Fe 2+. Plant J 45:335-346. doi: 10.1111/j.1365-

1285 $313 X .2005 .02624 . x$

1286

John SG, Geis RW, Saito M a., Boyle E a. (2007) Zinc isotope fractionation during high-affinity

1287 and low-affinity zinc transport by the marine diatom Thalassiosira oceanica. Limnol

1288 Oceanogr 52:2710-2714. doi: 10.4319/lo.2007.52.6.2710

1289

Johnson CM , Skulan JL, Beard BL, et al (2002) Isotopic fractionation between Fe(III) and Fe(II) in

1290 aqueous solutions. Earth Planet Sci Lett 195:141-153. doi: 10.1016/S0012-

1291 $821 \times(01) 00581-7$

1292 Jolley VD, Brown JC (1989) Iron efficient and inefficient oats. I. Differences in phytosiderophore 1293 release. J Plant Nutr 12:423-435. doi: http://dx.doi.org/10.1080/01904168909363963

1294 Jouvin D, Weiss DJ, Mason TFM, et al (2012) Stable isotopes of Cu and Zn in higher plants:

1295 evidence for Cu reduction at the root surface and two conceptual models for isotopic 1296 fractionation processes. Environ Sci Technol 46:2652-60. doi: 10.1021/es202587m

1297 Jung H, Gayomba SR, Rutzke M A, et al (2012) COPT6 is a plasma membrane transporter that 1298 functions in copper homeostasis in Arabidopsis and is a novel target of SQUAM OSA promoter-binding protein-like 7. J Biol Chem 287:33252-67. doi: 10.1074/jbc.M 112.397810

Kazakou E, Adamidis GC, Baker AJM , et al (2010) Species adaptation in serpentine soils in Lesbos Island (Greece): metal hyperaccumulation and tolerance. Plant Soil 332:369-385. doi: 10.1007/s11104-010-0302-9

1304 Kiczka M, Wiederhold JG, Frommer J, et al (2010a) Iron isotope fractionation during proton1305 and ligand-promoted dissolution of primary phyllosilicates. Geochim Cosmochim Acta 74:3112-3128. doi: 10.1016/j.gca.2010.02.018 
Kiczka M, Wiederhold JG, Kraemer SM, et al (2010b) Iron isotope fractionation during Fe uptake and translocation in alpine plants. Environ Sci Technol 44:6144-50. doi: $10.1021 /$ es100863b

Kimball BE, Mathur R, Dohnalkova AC, et al (2009) Copper isotope fractionation in acid mine drainage. Geochim Cosmochim Acta 73:1247-1263. doi: 10.1016/j.gca.2008.11.035

Kobae Y, Uemura T, Sato M H, et al (2004) Zinc transporter of Arabidopsis thaliana AtM TP1 is localized to vacuolar membranes and implicated in zinc homeostasis. Plant Cell Physiol 45:1749-58. doi: 10.1093/pcp/pci015

Koike S, Inoue H, Mizuno D, et al (2004) OsYSL2 is a rice metal-nicotianamine transporter that is regulated by iron and expressed in the phloem. Plant J 39:415-24. doi: 10.1111/j.1365$313 X .2004 .02146 . x$

Korshunova YO, Eide D, Clark WG, et al (1999) The IRT1 protein from Arabidopsis thaliana is a metal transporter with a broad substrate range. Plant M ol Biol 40:37-44. doi:

Kozhevnikova AD, Seregin I V, Erlikh NT, et al (2014) Histidine-mediated xylem loading of zinc is a species-wide character in Noccaea caerulescens. New Phytol 203:508-19. doi:

1324

Kumssa DB, Joy EJM , Ander EL, et al (2015) Dietary calcium and zinc deficiency risks are decreasing but remain prevalent. Sci Rep 5:10974. doi: 10.1038/srep10974

Küpper H, Jie Zhao F, M cGrath S (1999) Cellular compartmentation of zinc in leaves of the hyperaccumulator Thlaspi caerulescens. Plant Physiol 119:305-12. doi: 10.1104/pp.119.1. 305

Küpper H, Kochian LV (2010) Transcriptional regulation of metal transport genes and mineral nutrition during acclimatization to cadmium and zinc in the $\mathrm{Cd} / \mathrm{Zn}$ hyperaccumulator, Thlaspi caerulescens (Ganges population). New Phytol 185:114-29. doi: 10.1111/j.14698137.2009.03051.x 
1333 Lambers H, Hayes PE, Laliberté E, et al (2015) Leaf manganese accumulation and phosphorus1334 acquisition efficiency. Trends Plant Sci 20:83-90. doi: 10.1016/j.tplants.2014.10.007

1335 Lanquar V, Ramos M S, Lelièvre F, et al (2010) Export of vacuolar manganese by AtNRAM P3 and 1336 AtNRAM P4 is required for optimal photosynthesis and growth under manganese 1337 deficiency. Plant Physiol 152:1986-99. doi: 10.1104/pp.109.150946

1338 Lasat M M, Baker A, Kochian L V. (1996) Physiological Characterization of Root Zn2+Absorption 1339 and Translocation to Shoots in Zn Hyperaccumulator and Nonaccumulator Species of $1340 \quad$ Thlaspi. Plant Physiol 112:1715-1722. doi: 10.1104/pp.112.4.1715

1341 Lasat M M, Pence NS, Garvin DF, et al (2000) M olecular physiology of zinc transport in the Zn 1342 hyperaccumulator Thlaspi caerulescens. J Exp Bot 51:71-9. doi:

$1343 \quad 10.1093 /$ jexbot/51.342.71

1344 Lee S, Jeong HJ, Kim SA, et al (2010) OsZIP5 is a plasma membrane zinc transporter in rice. $1345 \quad$ Plant Mol Biol 73:507-17. doi: 10.1007/s11103-010-9637-0

1346 Lin Y-F, Aarts M GM (2012) The molecular mechanism of zinc and cadmium stress response in $1347 \quad$ plants. Cell M ol Life Sci 69:3187-206. doi: 10.1007/s00018-012-1089-z

1348 Lin Y-F, Liang H-M, Yang S-Y, et al (2009) Arabidopsis IRT3 is a zinc-regulated and plasma 1349 membrane localized zinc/iron transporter. New Phytol 182:392-404. doi: 10.1111/j.14691350 8137.2009.02766.x

1351

Lombi E, Zhao FJ, M cGrath SP, et al (2001) Physiological evidence for a high-affinity cadmium transporter highly expressed in a Thlaspi caerulescens ecotype. New Phytol 149:53-60. doi: 10.1046/j.1469-8137.2001.00003.x

1354

Lu L, Liao X, Labavitch J, et al (2014) Speciation and localization of Zn in the hyperaccumulator Sedum alfredii by extended X-ray absorption fine structure and micro-X-ray fluorescence.

1356

1357 Plant Physiol Biochem PPB / Société Fr Physiol végétale 84:224-32. doi:

1358 Lubkowitz M (2011) The Oligopeptide Transporters: A Small Gene Family with a Diverse Group 
1360 M aréchal CN, Télouk P, Albarède F (1999) Precise analysis of copper and zinc isotopic 1361 compositions by plasma-source mass spectrometry. Chem Geol 156:251-273. doi: 10.1016/S0009-2541(98)00191-0

1363 M aret W (2013) Zinc biochemistry: from a single zinc enzyme to a key element of life. Adv Nutr 1364 4:82-91. doi: 10.3945/an.112.003038

1365

Maret W (2015) Analyzing free zinc(II) ion concentrations in cell biology with fluorescent chelating molecules. Metallomics 7:202-11. doi: 10.1039/c4mt00230j

1367

M ariotti A, M ariotti F, Champigny ML, et al (1982) Nitrogen Isotope Fractionation Associated with Nitrate Reductase Activity and Uptake of NO(3) by Pearl Millet. Plant Physiol 69:880-4. doi: 0032-0889/82/69/0880/05/\$00.50/0

Markovic T, Manzoor S, Humphreys-Williams E, et al (2016) Experimental determination of zinc isotope fractionation in complexes with the phytosiderophore 2'-deoxymugeneic acid (DMA) and its structural analogues, and implications for plant uptake mechanisms. Environ Sci Technol acs.est.6b00566. doi: 10.1021/acs.est.6b00566

1374 Marschner H (1995) M ineral Nutrition of Higher Plants, Second. Academic Press, London 1375 M arschner H, Römheld V, Kissel M (1986) Different strategies in higher plants in mobilization and uptake of iron. J Plant Nutr 9:695-713. doi: 10.1080/01904168609363475

1377 M attiello EM, Ruiz HA, Neves JCL, et al (2015) Zinc deficiency affects physiological and anatomical characteristics in maize leaves. J Plant Physiol 183:138-43. doi: 10.1016/j.jplph.2015.05.014

M edas D, De Giudici G, Casu MA, et al (2015) M icroscopic Processes Ruling the Bioavailability of Zn to Roots of Euphorbia pithyusa L. Pioneer Plant. Environ Sci Technol 49:1400-1408. doi: $10.1021 /$ es503842w

1383 M ekhtiyeva VL, Pankina RG (1968) Isotopic composition of sulfur in aquatic plants and 1384 dissolved sulfates. Geochemistry Int 624-627. 
1385 M eng F, Liu D, Yang X, et al (2014) Zinc uptake kinetics in the low and high-affinity systems of

1386 two contrasting rice genotypes. J Plant Nutr Soil Sci 177:412-420. doi:

$1387 \quad$ 10.1002/jpln.201200621

1388 M enguer PK, Farthing E, Peaston KA, et al (2013) Functional analysis of the rice vacuolar zinc

1389 transporter OsM TP1. J Exp Bot 64:2871-83. doi: 10.1093/jxb/ert136

1390 M ilner MJ, Craft E, Yamaji N, et al (2012) Characterization of the high affinity Zn transporter

1391 from Noccaea caerulescens, NcZNT1, and dissection of its promoter for its role in Zn

1392 uptake and hyperaccumulation. New Phytol 195:113-23. doi: 10.1111/j.1469-

1393 8137.2012.04144.x

1394

M oeller K, Schoenberg R, Pedersen R-B, et al (2012) Calibration of the New Certified Reference M aterials ERM -AE633 and ERM -AE647 for Copper and IRM M -3702 for Zinc Isotope

1396

1397 Amount Ratio Determinations. Geostand Geoanalytical Res 36:177-199. doi:

1398 10.1111/j.1751-908X.2011.00153.x

M onsant AC, Kappen P, Wang Y, et al (2011) In vivo speciation of zinc in Noccaea caerulescens in response to nitrogen form and zinc exposure. Plant Soil 348:167-183. doi:

1400 $10.1007 /$ s11104-011-0887-7

1401

Morel M, Crouzet J, Gravot A, et al (2009) AtHM A3, a P1B-ATPase allowing Cd/Zn/Co/Pb vacuolar storage in Arabidopsis. Plant Physiol 149:894-904. doi: 10.1104/pp.108.130294

1403 M oynier F, Fujii T, Wang K, Foriel J (2013) Ab initio calculations of the Fe(II) and Fe(III) isotopic 1404 effects in citrates, nicotianamine, and phytosiderophore, and new Fe isotopic measurements in higher plants. Comptes rendus - Geosci 345:230-240. doi:

1406 10.1016/j.crte.2013.05.003

M oynier F, Pichat S, Pons M L, et al (2009) Isotopic fractionation and transport mechanisms of Zn in plants. Chem Geol 267:125-130. doi: 10.1016/j.chemgeo.2008.09.017

1409 M ukherjee I, Campbell NH, Ash JS, Connolly EL (2006) Expression profiling of the Arabidopsis 1410 ferric chelate reductase (FRO) gene family reveals differential regulation by iron and 
1412 Müller C, Kuki KN, Pinheiro DT, et al (2015) Differential physiological responses in rice upon exposure to excess distinct iron forms. Plant Soil 391:123-138. doi: 10.1007/s11104-015$2405-9$

M urakami T, Ise K, Hayakawa M, et al (1989) Stabilities of metal complexes of mugineic acids and their specific affinities for iron(III). Chem Lett 2137-2140. doi: 10.1246/ cl.1989.2137

1417 M urata Y, Ma JF, Yamaji N, et al (2006) A specific transporter for iron(III)-phytosiderophore in barley roots. Plant J 46:563-72. doi: 10.1111/j.1365-313X.2006.02714.X

1419

Neelam K, Tiwari VK, Rawat N, et al (2010) Identification of Aegilops species with higher production of phytosiderophore and iron and zinc uptake under micronutrient-sufficient

1421 and -deficient conditions. Plant Genet Resour 8:132-141. doi:

1423

Neue HU, Lantin RS (1994) M icronutrient toxicities and deficiencies in rice. In: Yeo AR, Flowers $1424 \quad \mathrm{~T}$ (eds) Soil M ineral Stresses. Springer-Verlag, Berlin, pp 175-200

1425 Neumann D, zur Nieden U (2001) Silicon and heavy metal tolerance of higher plants.

1426 Phytochemistry 56:685-92. doi: 10.1016/S0031-9422(00)00472-6

1427 Nishiyama R, Kato M, Nagata S, et al (2012) Identification of Zn-nicotianamine and Fe-2'-

1428 Deoxymugineic acid in the phloem sap from rice plants (Oryza sativa L.). Plant Cell Physiol 53:381-90. doi: 10.1093/pcp/pcr188

1430 Ó Lochlainn S, Bowen HC, Fray RG, et al (2011) Tandem quadruplication of HM A4 in the zinc (Zn) and cadmium (Cd) hyperaccumulator Noccaea caerulescens. PLoS One 6:e17814. doi: 10.1371/journal.pone.0017814

Oburger E, Gruber B, Schindlegger Y, et al (2014) Root exudation of phytosiderophores from soil-grown wheat. New Phytol 203:1161-74. doi: 10.1111/nph.12868 Plant Sci 5:30. doi: 10.3389/fpls.2014.00030 
1437 Orera I, Rodríguez-Castrillón J a, M oldovan M , et al (2010) Using a dual-stable isotope tracer

1438 method to study the uptake, xylem transport and distribution of Fe and its chelating

1439 agent from stereoisomers of an Fe(III)-chelate used as fertilizer in Fe-deficient Strategy I

1440 plants. Metallomics 2:646-57. doi: 10.1039/c0mt00018c

1441 Ova EA, Kutman UB, Ozturk L, Cakmak I (2015) High phosphorus supply reduced zinc

1442 concentration of wheat in native soil but not in autoclaved soil or nutrient solution. Plant

1443 Soil 393:147-162. doi: 10.1007/s11104-015-2483-8

1444 Papoyan A, Kochian LV (2004) Identification of Thlaspi caerulescens genes that may be

1445 involved in heavy metal hyperaccumulation and tolerance. Characterization of a novel

1446 heavy metal transporting ATPase. Plant Physiol 136:3814-23. doi:

$1447 \quad 10.1104 / p p .104 .044503$

1448 Pedler JF, Parker DR, Crowley DE (2000) Zinc deficiency-induced phytosiderophore release by

1449 the Triticaceae is not consistently expressed in solution culture. Planta 211:120-6. doi:

$1450 \quad 10.1007 / \mathrm{s} 004250000270$

1451 Pence NS, Larsen PB, Ebbs SD, et al (2000) The molecular physiology of heavy metal transport

1452 in the Zn/Cd hyperaccumulator Thlaspi caerulescens. Proc Natl Acad Sci U SA 97:4956-

$1453 \quad$ 60. doi: $10.1073 /$ pnas.97.9.4956

1454 PengJ-S, GongJ-M (2014) Vacuolar sequestration capacity and long-distance metal transport

1455 in plants. Front Plant Sci 5:19. doi: 10.3389/fpls.2014.00019

1456 Podar D, Scherer J, Noordally Z, et al (2012) Metal selectivity determinants in a family of

1457 transition metal transporters. J Biol Chem 287:3185-96. doi: 10.1074/jbc.M 111.305649

1458 Prasad MNV, De Oliveira Freitas HM (2003) Metal hyperaccumulation in plants - Biodiversity

1459 prospecting for phytoremediation technology. Electron J Biotechnol 6:0-0. doi:

$1460 \quad 10.2225 /$ vol6-issue3-fulltext-6

1461 Ptashnyk M, Roose T, Jones DL, Kirk GJD (2011) Enhanced zinc uptake by rice through

1462 phytosiderophore secretion: a modelling study. Plant Cell Environ 34:2038-46. doi: 
1464 Quinet M, Vromman D, Clippe A, et al (2012) Combined transcriptomic and physiological 1465 approaches reveal strong differences between short- and long-term response of rice 1466 (Oryza sativa) to iron toxicity. Plant Cell Environ 35:1837-59. doi: 10.1111/j.13653040.2012.02521.x

Rasouli-Sadaghiani M, Sadeghzadeh B, Sepehr E, Rengel Z (2011) Root Exudation and Zinc Uptake By Barley Genotypes Differing in Zn Efficiency. J Plant Nutr 34:1120-1132. doi: $10.1080 / 01904167.2011 .558156$

Rellán-Alvarez R, Abadía J, Alvarez-Fernández A (2008) Formation of metal-nicotianamine complexes as affected by $\mathrm{pH}$, ligand exchange with citrate and metal exchange. A study by electrospray ionization time-of-flight mass spectrometry. Rapid Commun Mass Spectrom 22:1553-62. doi: 10.1002/rcm.3523

Rellán-Alvarez R, Giner-M artínez-Sierra J, Orduna J, et al (2010) Identification of a tri-iron(III), tri-citrate complex in the xylem sap of iron-deficient tomato resupplied with iron: new insights into plant iron long-distance transport. Plant Cell Physiol 51:91-102. doi:

Remy E, Cabrito TR, Batista RA, et al (2014) Intron retention in the 5'UTR of the novel ZIF2 transporter enhances translation to promote zinc tolerance in arabidopsis. PLoS Genet 10:e1004375. doi: 10.1371/journal.pgen.1004375

Rengel Z (1999) Physiological responses of wheat genotypes grown in chelator-buffered nutrient solutions with increasing concentrations of excess HEDTA. Plant Soil 215:193202. doi: 10.1023/A:1004595112969

Rengel Z, Römheld V (2000) Root exudation and Fe uptake and transport in wheat genotypes differing in tolerance to Zn deficiency. Plant Soil 222:25-34. doi: 10.1023/A:1004799027861

1488 Rengel Z, Romheld V, M arschner H (1998) Uptake of Zinc and Iron by Wheat Genotypes 

$10.1016 / \mathrm{S} 0176-1617(98) 80260-5$

1491 Ricachenevsky FK, M enguer PK, Sperotto RA, et al (2013) Roles of plant metal tolerance 1492 proteins (M TP) in metal storage and potential use in biofortification strategies. Front $1493 \quad$ Plant Sci 4:144. doi: 10.3389/fpls.2013.00144

1494 Ricachenevsky FK, M enguer PK, Sperotto RA, Fett JP (2015) Got to hide your Zn away:

1495 Molecular control of Zn accumulation and biotechnological applications. Plant Sci 236:1-

1496 17. doi: 10.1016/j.plantsci.2015.03.009

1497 Roberts LA, Pierson AJ, Panaviene Z, Walker EL (2004) Yellow stripe1. Expanded roles for the 1498 maize iron-phytosiderophore transporter. Plant Physiol 135:112-20. doi:

$1499 \quad 10.1104 /$ pp.103.037572

1500 Robinson NJ, Procter CM, Connolly EL, Guerinot ML (1999) A ferric-chelate reductase for iron 1501 uptake from soils. Nature 397:694-7. doi: 10.1038/17800

1502 Römheld V, M arschner H (1981) Effect of Fe stress on utilization of Fe chelates by efficient and 1503 inefficient plant species. J Plant Nutr 3:551-560. doi: 10.1080/01904168109362860

1504 Ryan BM , Kirby JK, Degryse F, et al (2013) Copper speciation and isotopic fractionation in 1505 1506 1507 1508 plants: Uptake and translocation mechanisms. New Phytol 199:367-378. doi: $10.1111 /$ nph.12276

Salt DE, Prince RC, Baker AJM, et al (1999) Zinc Ligands in the M etal Hyperaccumulator Thlaspi caerulescens As Determined Using X-ray Absorption Spectroscopy. Environ Sci Technol 33:713-717. doi: 10.1021/es980825x

Sancenón V, Puig S, Mateu-Andrés I, et al (2004) The Arabidopsis copper transporter COPT1 functions in root elongation and pollen development. J Biol Chem 279:15348-55. doi:

1513 Santi S, Schmidt W (2009) Dissecting iron deficiency-induced proton extrusion in Arabidopsis 1514 roots. New Phytol 183:1072-84. doi: 10.1111/j.1469-8137.2009.02908.x 
1515 Sarret G, Saumitou-Laprade P, Bert V, et al (2002) Forms of zinc accumulated in the

1516 hyperaccumulator Arabidopsis halleri. Plant Physiol 130:1815-26. doi:

$1517 \quad 10.1104 / p p .007799$

1518 Schaaf G, Ludewig U, Erenoglu BE, et al (2004) ZmYS1 functions as a proton-coupled symporter 1519 for phytosiderophore- and nicotianamine-chelated metals. J Biol Chem 279:9091-6. doi: 10.1074/jbc.M 311799200

1521

Schneider T, Persson DP, Husted S, et al (2013) A proteomics approach to investigate the process of Zn hyperaccumulation in Noccaea caerulescens (J \& C. Presl) F.K. Meyer. Plant J 73:131-42. doi: 10.1111/tpj.12022

1524

Shahzad Z, Gosti F, Frérot H, et al (2010) The five AhM TP1 zinc transporters undergo different evolutionary fates towards adaptive evolution to zinc tolerance in Arabidopsis halleri. PLoS Genet 6:e1000911. doi: 10.1371/journal.pgen.1000911

1527

Shane MW, Lambers H (2005) Manganese accumulation in leaves of Hakea prostrata (Proteaceae) and the significance of cluster roots for micronutrient uptake as dependent on phosphorus supply. Physiol Plant 124:441-450. doi: 10.1111/j.1399-

1530 3054.2005.00527.x

1531

1532

Shen J, Zeng Y, Zhuang X, et al (2013) Organelle pH in the Arabidopsis endomembrane system.

1533 Mol Plant 6:1419-37. doi: 10.1093/mp/sst079

Sinclair SA, Krämer U (2012) The zinc homeostasis network of land plants. Biochim Biophys Acta - Mol Cell Res 1823:1553-1567. doi: 10.1016/j.bbamcr.2012.05.016

Singh B, Singh BK (2011) Effect of Reduced Seed and Applied Znc on Zinc Efficiency of Wheat Genotypes Under Zinc Deficiency in Nutrient Solution Culture. J Plant Nutr 34:449-464. doi: 10.1080/01904167.2011.536884

1538 Smith RM, Martell AE (1989) Critical Stability Constants. Springer US, Boston, M A

1539 Smolders E, Versieren L, Shuofei D, et al (2013) Isotopic fractionation of Zn in tomato plants 1540 suggests the role of root exudates on Zn uptake. Plant Soil 370:605-613. doi: 
1542 Song W-Y, Choi KS, Kim DY, et al (2010) Arabidopsis PCR2 is a zinc exporter involved in both 1543 zinc extrusion and long-distance zinc transport. Plant Cell 22:2237-2252. doi:

$1544 \quad 10.1105 /$ tpc.109.070185

1545 Straczek A, Sarret G, M anceau A, et al (2008) Zinc distribution and speciation in roots of 1546 various genotypes of tobacco exposed to Zn. Environ Exp Bot 63:80-90. doi: 10.1016/j.envexpbot.2007.10.034

Sunda WG, Huntsman SA (1992) Feedback interactions between zinc and phytoplankton in seawater. Limnol Oceanogr 37:25-40. doi: 10.4319/lo.1992.37.1.0025

Suzuki M, Bashir K, Inoue H, et al (2012) Accumulation of starch in Zn-deficient rice. Rice 5:9. doi: 10.1186/1939-8433-5-9

Suzuki M, Takahashi M, Tsukamoto T, et al (2006) Biosynthesis and secretion of mugineic acid family phytosiderophores in zinc-deficient barley. Plant J 48:85-97. doi: 10.1111/j.1365$313 \times .2006 .02853 . x$

Suzuki M, Tsukamoto T, Inoue H, et al (2008) Deoxymugineic acid increases Zn translocation in Zn-deficient rice plants. Plant M ol Biol 66:609-17. doi: 10.1007/s11103-008-9292-x

Takagi S (1976) Naturally occurring iron-chelating compounds in oat- and rice-root washings. Soil Sci Plant Nutr 22:423-433. doi: 10.1080/00380768.1976.10433004

1559

1560

1561

Takagi S, Nomoto K, Takemoto T (2008) Physiological aspect of mugineic acid, a possible phytosiderophore of graminaceous plants. J Plant Nutr 7:469-477. doi: $10.1080 / 01904168409363213$

Tang Y-T, Cloquet C, Deng T-H-B, et al (2016) Zinc Isotope Fractionation in the Hyperaccumulator Noccaea caerulescens and the Nonaccumulating Plant Thlaspi arvense at Low and High Zn Supply. Environ Sci Technol 50:8020-8027. doi: 10.1021/acs.est.6b00167

1566 Tang YT, Cloquet C, Sterckeman T, et al (2012) Fractionation of stable zinc isotopes in the field- 
grown zinc hyperaccumulator Noccaea caerulescens and the zinc-tolerant plant silene vulgaris. Environ Sci Technol 46:9972-9979. doi: 10.1021/es3015056

Tauris B, Borg S, Gregersen PL, Holm PB (2009) A roadmap for zinc trafficking in the developing barley grain based on laser capture microdissection and gene expression profiling. J Exp Bot 60:1333-47. doi: 10.1093/jxb/erp023

Tennstedt P, Peisker D, Böttcher C, et al (2009) Phytochelatin synthesis is essential for the detoxification of excess zinc and contributes significantly to the accumulation of zinc. Plant Physiol 149:938-48. doi: 10.1104/pp.108.127472

Tiong J, M cDonald GK, Genc Y, et al (2014) HvZIP7 mediates zinc accumulation in barley (Hordeum vulgare) at moderately high zinc supply. New Phytol 201:131-43. doi: $10.1111 /$ nph.12468

Tolay I, Erenoglu B, Römheld V, et al (2001) Phytosiderophore release in Aegilops tauschii and Triticum species under zinc and iron deficiencies. J Exp Bot 52:1093-9. doi:

1581 Trampczynska A, Küpper H, M eyer-Klaucke W, et al (2010) Nicotianamine forms complexes 1582 with Zn(II) in vivo. Metallomics 2:57-66. doi: 10.1039/b913299f

1583 Tsednee M, Huang Y-C, Chen Y-R, Yeh K-C (2016) Identification of metal species by ESI-M S/MS 1584 1585 through release of free metals from the corresponding metal-ligand complexes. Sci Rep 6:26785. doi: 10.1038/srep26785

Tsednee M, Yang S-C, Lee D-C, Yeh K-C (2014) Root-secreted nicotianamine from Arabidopsis halleri facilitates zinc hypertolerance by regulating zinc bioavailability. Plant Physiol 166:839-52. doi: 10.1104/pp.114.241224

Ueno D, Yamaji N, M a JF (2009) Further characterization of ferric-phytosiderophore transporters ZmYS1 and HvYS1 in maize and barley. J Exp Bot 60:3513-20. doi:

1592 Vallee BL, Auld DS (1992) Functional zinc-binding motifs in enzymes and DNA-binding proteins. 
1594 Van Breemen N, Castro RU (1980) Zinc deficiency in wetland rice along a toposequence of 1595 hydromorphic soils in the Philippines. Plant Soil 57:215-221. doi: 10.1007/BF02211681 1596 van der Mark F, van den Briel M L, van Oers JW, Bienfait HF (1982) Ferritin in bean leaves with 1597 constant and changing iron status. Planta 156:341-4. doi: 10.1007/BF00397472

Vanhaecke F, Balcaen L, M alinovsky D (2009) Use of single-collector and multi-collector ICPmass spectrometry for isotopic analysis. J Anal At Spectrom 24:863. doi: $10.1039 / \mathrm{b} 903887 f$

1601

Vert G, Grotz N, Dédaldéchamp F, et al (2002) IRT1, an Arabidopsis transporter essential for 1602 iron uptake from the soil and for plant growth. Plant Cell 14:1223-33. doi: 10.1105/tpc.

1603 001388

1604

Viers J, Oliva P, Nonell A, et al (2007) Evidence of Zn isotopic fractionation in a soil-plant

1605

1606 system of a pristine tropical watershed (Nsimi, Cameroon). Chem Geol 239:124-137. doi:

1607 Viers J, Prokushkin AS, Pokrovsky OS, et al (2015) Zn isotope fractionation in a pristine larch 1608 forest on permafrost-dominated soils in Central Siberia. Geochem Trans 16:3. doi:

1609 $10.1186 /$ s12932-015-0018-0

1610

1611

von Wiren N, Klair S, Bansal S, et al (1999) Nicotianamine chelates both Felll and Fell.

1612 Implications for metal transport in plants. Plant Physiol 119:1107-14. doi: 10.1104/pp.

1613 Von Wiren N, M arschner H, Romheld V (1996) Roots of Iron-Efficient M aize also Absorb 1614 Phytosiderophore-Chelated Zinc. Plant Physiol 111:1119-1125. doi: 10.1104/pp.111.4.

1615 1119

1616 Weinstein C, M oynier F, Wang K, et al (2011) Isotopic fractionation of Cu in plants. Chem Geol 286:266-271. doi: 10.1016/j.chemgeo.2011.05.010

1618 Weiss DJ, Mason TFD, Zhao FJ, et al (2005) Isotopic discrimination of zinc in higher plants. New 
Phytol 165:703-710. doi: 10.1111/j.1469-8137.2004.01307.x

1620 Wessells KR, Brown KH (2012) Estimating the global prevalence of zinc deficiency: results

1621 based on zinc availability in national food supplies and the prevalence of stunting. PLoS

1622 One 7:e50568. doi: 10.1371/journal.pone.0050568

1623

White PJ, Whiting SN, Baker AJM, Broadley MR (2002) Does Zinc M ove Apoplastically to the Xylem in Roots of Thlaspi caerulescens? on JSTOR. In: New Phytol. http://www.jstor.org/stable/1513787?seq=1\#page_scan_tab_contents. Accessed 19 M ay 2016

1627

White WM (2015) Isotope geochemistry, 1st edn. John Wiley $\&$ Sons

Widodo B, Broadley M R, Rose T, et al (2010) Response to zinc deficiency of two rice lines with contrasting tolerance is determined by root growth maintenance and organic acid exudation rates, and not by zinc-transporter activity. New Phytol 186:400-14. doi: 10.1111/j.1469-8137.2009.03177.x

Wiederhold JG, Kraemer SM, Teutsch N, et al (2006) Iron isotope fractionation during protonpromoted, ligand-controlled, and reductive dissolution of Goethite. Environ Sci Technol 40:3787-93. doi: 10.1021/es052228y

Wiegand BA (2005) Ca cycling and isotopic fluxes in forested ecosystems in Hawaii. Geophys Res Lett 32:L11404. doi: 10.1029/2005GL022746

Wilkinson, Janet E. Corlett, Ludovic Oger WJD, Corlett, Oger, Davies (1998) Effects of xylem pH on transpiration from wild-type and flacca tomato leaves. A vital role for abscisic acid in preventing excessive water loss even from well-watered plants. Plant Physiol 117:703-9. doi: 10.1104/pp.117.2.703

1641 Wintz H, Fox T, Wu Y, et al (2003) Expression profiles of Arabidopsis thaliana in mineral 1642 deficiencies reveal novel transporters involved in metal homeostasis. - PubM ed - NCBI. 1643 In: J. Biol. Chem. http:// www.ncbi.nlm.nih.gov/pubmed/13129917. Accessed $30 \mathrm{M}$ ar 2016 
1645 Wissuwa M, Ismail AM, Yanagihara S (2006) Effects of zinc deficiency on rice growth and

1646 genetic factors contributing to tolerance. Plant Physiol 142:731-741. doi:

$1647 \quad 10.1104 /$ pp.106.085225

1648 Wu C, Lu L, Yang X, et al (2010) Uptake, translocation, and remobilization of zinc absorbed at 1649 different growth stages by rice genotypes of different Zn densities. J Agric Food Chem 58:6767-73. doi: 10.1021/jf100017e

1651

Xuan Y, Scheuermann EB, M eda AR, et al (2006) Separation and identification of phytosiderophores and their metal complexes in plants by zwitterionic hydrophilic interaction liquid chromatography coupled to electrospray ionization mass spectrometry. J Chromatogr A 1136:73-81. doi: 10.1016/j.chroma.2006.09.060

1655

1656

1657

Yamaji N, Xia J, M itani-Ueno N, et al (2013) Preferential delivery of zinc to developing tissues in rice is mediated by P-type heavy metal ATPase OsHM A2. Plant Physiol 162:927-39. doi: 10.1104/pp.113.216564

Yoneyama T, Gosho T, Kato M, et al (2010) Xylem and phloem transport of Cd, Zn and Fe into the grains of rice plants ( Oryza sativa L.) grown in continuously flooded Cd-contaminated soil. Soil Sci Plant Nutr 56:445-453. doi: 10.1111/j.1747-0765.2010.00481.x

Zhang F, Römheld V, M arschner H (1989) Effect of zinc deficiency in wheat on the release of zinc and iron mobilizing root exudates. Zeitschrift für Pflanzenernährung und Bodenkd 152:205-210. doi: 10.1002/jpln.19891520211

Zhang W, Liu D, Liu Y, et al (2016) Zinc uptake and accumulation in winter wheat relative to changes in root morphology and mycorrhizal colonization following varying phosphorus application on calcareous soil. F Crop Res 197:74-82. doi: 10.1016/j.fcr.2016.08.010

Zhang X, Zhang F, Mao D (1998) Effect of iron plaque outside roots on nutrient uptake by rice (Oryza sativa L.). Zinc uptake by Fe-deficient rice. Plant Soil 202:33-39. doi: 10.1023/A:1004322130940

1670 Zhang Y, Xu Y-H, Yi H-Y, Gong J-M (2012) Vacuolar membrane transporters OsVIT1 and OsVIT2 
1671 modulate iron translocation between flag leaves and seeds in rice. Plant J 72:400-10. doi:

$1672 \quad 10.1111 / j .1365-313 X .2012 .05088 . x$

1673 Zheng L, Yamaji N, Yokosho K, M J JF (2012) YSL16 is a phloem-localized transporter of the 1674 copper-nicotianamine complex that is responsible for copper distribution in rice. Plant $1675 \quad$ Cell 24:3767-82. doi: 10.1105/tpc.112.103820

1676 